\title{
International Federation of Red Cross and Red Crescent Societies
}

\author{
Strategy 2010 - Health \& Care Review
}

December 2004 - January 2005

\section{Dr Markus Michael}

With contribution of peer reviewers Dr Asha Mohammed, Kenyan Red Cross; Dr Salvador A. Molina, Cruz Roja Salvadoreña Dr. Ophelia Kachatryan, Armenian Red Cross.

This report has been produced at the request of the Federation and financed by it. The comments contained herein reflect the opinions of the consultants only. 
Strategy 2010 - Health \& Care Review

\section{Acknowledgements}

The external consultant and the peer reviewers made ample use of the facilities, support and information offered by and gratefully accepted from offices and staff of the Federation and National Societies. During the briefing in Geneva and throughout the field trip, essential background information and orientation were readily provided. The evaluators express their gratitude to all those - RC staff, partners, beneficiaries and external actors - that kindly gave their time, contribution and hospitality. 


\section{Acronyms and abbreviations}

$\begin{array}{ll}\text { ARCHI } & \text { African Red Cross and Red Crescent Health Initiative } \\ \text { CBFA } & \text { Community Based First Aid } \\ \text { CDC } & \text { Center for Disease Control } \\ \text { CORI } & \text { Comité Regional Interamericano } \\ \text { DOTS } & \text { Directly Observed Treatment, Short-course } \\ \text { EPI } & \text { Expanded Programme of Immunisation } \\ \text { ERNA } & \text { European Red Cross and Red Crescent Network on HIV/AIDS } \\ \text { Federation } & \text { International Federation of Red Cross and Red Crescent Societies } \\ \text { GFATM } & \text { Global Fund to Fight AIDS, TB and Malaria } \\ \text { GNP+ } & \text { Global Network of People Living with HIV and AIDS } \\ \text { H\&C } & \text { Health \& Care in the Community } \\ \text { IMCI } & \text { Integrated Management of Childhood Illnesses } \\ \text { KAP } & \text { Knowledge, Attitude and Practices } \\ \text { MCH } & \text { Mother and Child Health } \\ \text { MDG } & \text { Millennium Development Goals } \\ \text { MoH } & \text { Ministry of Health } \\ \text { MoU } & \text { Memorandum of Understanding } \\ \text { NS } & \text { National (Cross or Red Crescent) Society } \\ \text { OD } & \text { Organisational Development } \\ \text { OVC } & \text { Orphans and Vulnerable Children } \\ \text { PAHO } & \text { Pan-American Health Organisation } \\ \text { PLWHA } & \text { People Living with HIV/AIDS } \\ \text { PNS } & \text { Participating National Society } \\ \text { RC } & \text { Red Cross / Red Crescent } \\ \text { SG } & \text { Secretary General } \\ \text { UNGASS } & \text { UN General Assembly Special Session on AIDS } \\ \text { VCT } & \text { Voluntary Counselling and Testing } \\ \end{array}$




\section{Table of contents}

1. EXECUTIVE SUMMARY ............................................... 5

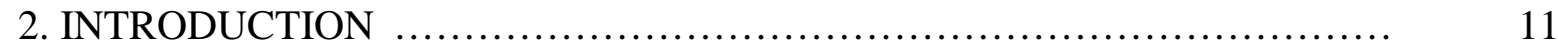

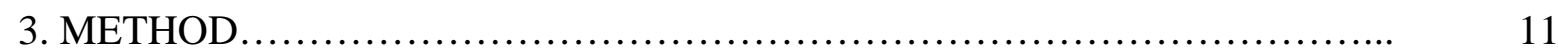

4. FINDINGS AND DISCUSSION....................................... 12

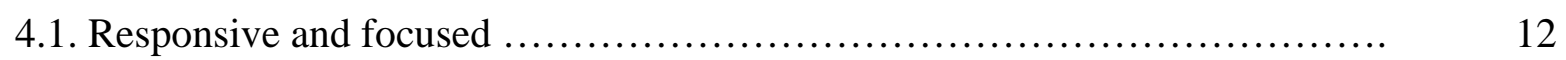

4.1.1. Global/regional level.............................................. 12

4.1.1.1. Millennium Development Goals and client outcomes...................... 12

4.1.1.2. Making Strategy 2010 operational.................................. 13

4.1.2. Country level.................................................... 14

4.1.2.1. Health \& Care: beyond disaster victims to 'structural vulnerability' ........... 14

4.1.2.2. Relevance of $\mathrm{H} \& \mathrm{C}$ activities...................................... $\quad 16$

4.1.2.3. Operational choices.............................................. 17

4.1.2.4. Planning process.................................................... 18

4.1.3. Operational level................................................. 20

4.1.3.1. Community / beneficiary involvement and satisfaction..................... 20

4.1.3.2. Programme implementation .................................... 20

4.2. Well-functioning National Society.................................... 21

4.2.1. Role of the Federation, the Regions and the Secretariat..................... 21

4.2.2. Country level........................................................ 23

4.2.2.1. Has Strategy 2010 made a difference? .................................. 23

4.2.2.2. The difference 'RC-ness' can make..................................... 24

4.2.2.3. Resource mobilisation for $\mathrm{H} \& \mathrm{C}$ programmes.............................. 24

4.2.2.4. H \& C Structure in the NS........................................... 25

4.2.3. Operational level: volunteer work.................................. 27

4.3. Working together effectively...................................... 29

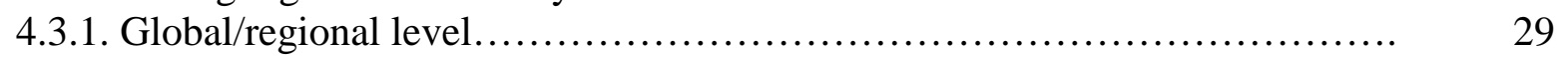

4.3.2. Country level.................................................. $\quad 30$

4.3.2.1 Working with others............................................... 30

4.3.2.2. PNSs ......................................................... 31

4.3.2.3. Relations to $\mathrm{MoH}$ and links with academic institutions.................... 32

4.3.3. Operational level................................................ 33

4.4. Health \& Care issues.................................................. 34

4.4.1. HIV/AIDS: NS presence in country response.......................... 34

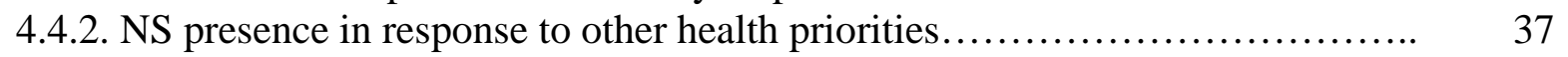

4.4.3. NS presence in 'traditional' activities.................................. 38

4.4.4. Water and Sanitation............................................ 39

4.5. Crosscutting ethical issues.......................................... 40

Annexes:

Annex A Terms of Reference

Annex B Inception report

Annex C References

Annex D Itinerary 


\section{EXECUTIVE SUMMARY}

\subsection{Introduction}

This thematic review of the area of Health \& Care in the Community forms part of the midterm review of Strategy 2010. The most famous among former dissidents of the Red Cross recently said: "La Croix-Rouge est vielle". This review was also a search for the rejuvenating capacity of the Red Cross /Red Crescent; positive signs were found.

The Federation has called unequal access to health "the Solferino of our time". Health \& Care $(\mathrm{H} \& \mathrm{C})$ programmes represent the biggest and a growing part within the activities of National $\mathrm{RC} / \mathrm{RC}$ Societies and the Federation

The review initiated with desk study and interviews at the Secretariat by the external consultant. Five National Societies were visited: in Nigeria, Honduras, Kazakhstan, Namibia, and Norway; the first three visits included peer reviewers. The bulk of the investigation consisted in semi-structured interviews with key informants and group interviews, which were often combined with site visits and direct observation. Fieldwork was complemented by document study and telephone interviews, mainly to (11) presidents or health co-ordinators of RC Societies. The review suffered from a number of operational difficulties.

Main conclusion:

- Owing to its serious methodological limitations (especially the small and biased sample and the small number of external respondents), the results presented are at best a 'snapshot review' with little claim to wider relevance. It can be hoped, however, that the review contributes to guide a final in-depth H\&C evaluation of Strategy 2010.

Main recommendation:

- For any follow-up review, the Federation should strive to achieve a representative sampling that includes possibly more NSs from all regions, and also the weaker ones. In order to enhance the learning effect, the inclusion of a peer reviewer of the Federation or the Secretariat is to be considered.

Main lesson learnt:

- The operational difficulties this review faced are liable to reflect difficulties faced by the Federation in its work as a membership organisation. Also, it proved often difficult if not impossible to separate $\mathrm{H} \& \mathrm{C}$ issues from wider organisational and structural issues.

\subsection{Responsive and focused}

The main conclusions were:

- Although the Millennium Development Goals (MDGs) were never referred to explicitly during the field visits, the $\mathrm{H} \& \mathrm{C}$ activities observed all contribute to achieve the MDGs. With the exception of rich NSs in rich countries, however, plenty of scope remains to contribute in 'neglected' areas such as improving maternal health.

- Strategy 2010 needs an active 'translation' into policy and a strategic framework. According to the degree of homogeneity and the means available, this can be - and has been - done by continent, region or country. Alternatively, a minimalist version is integration of the content of Strategy 2010 into individual country strategies. 
- The implementation of the shift beyond the traditional $\mathrm{RC}$ client as a disaster victim to the 'structurally vulnerable' can be - and has been - hindered by external and internal perception and lack of financial means. All NSs consulted, however, have made and are making considerable progress in this regard.

- For European NSs, the direction of influence was at least in part the other way round: from the NSs to Strategy 2010; this points at the responsibility of all NSs to continue contributing to policy formulation at Federation level.

- The task of defining who is most vulnerable is - correctly - being done at (sub-) regional or country level.

- $\mathrm{H} \& \mathrm{C}$ activities were found relevant to the beneficiaries, the $\mathrm{MoH}$ and the RC. The generally close and good relationship with the $\mathrm{MoH}$ observed and reported should guarantee that $\mathrm{H} \& \mathrm{C}$ activities continue to be in line with national health priorities, according to the capacity of NSs.

- For the making of operational choices, the existence of verified needs is a prerequisite. While the influence of external pressure was found rare, the availability of funding was found to be all-important. As for donors' preferences, 'relief' activities still appear to prime over 'development' activities, though with exceptions, e.g. for globally recognised pandemics and by development-conscious donors.

- The inclusion of other stakeholders for H\&C programme planning was found to be common practice, be it beneficiaries (often volunteers themselves), local organs of civil society, the $\mathrm{MoH}$ at all levels or UN organisations.

- Advocacy activities with regard to health and social welfare (of good quality) are conducted at sometimes impressive scale, for the general and specific publics. It can be argued that advocacy is on safer ground when supported by service delivery which appears mostly the case.

- Anecdotal evidence pointed at a high degree of community and beneficiary involvement by the respective NS, which is fostered by the way of working itself, i.e. through volunteers that are, after all, part of the community.

And the main recommendations:

- Visibility of RC contributions to the MDGs is to be enhanced by indicating their magnitude compared to the size of the problem; moreover, significantly more efforts must be made to measure and demonstrate outcome and impact.

- The Federation should make sure that every National Society has access to a (sub-) regional or local 'translation' of Strategy 2010 into a H\&C policy and a strategic framework adapted to (sub-) regional or local context.

- The Federation should continue enabling the NSs (and vice versa) to be the vanguard of civil society: acting in the community where the state cannot act, or not yet.

- A NS may not be able to tackle all health problems in a given country. However, within a given programmes and activities, efforts should be made to act as inclusively and holistically as possible. A caveat is indicated not to overlook other priorities in comparison to HIV/AIDS, where money flows easiest at present.

The main lesson learnt:

- If periodic re-assessment of vulnerabilities in society and of the state's capacity to overcome them are not undertaken, a NS risks being stuck with activities that are outof-date and/or out-of-mandate (e.g. private sector curative care). 


\subsection{Well-functioning National Society}

The main conclusions were:

- The Federation has often lived up to expectations of NSs with regard to policy formulation and technical assistance, less often with regard to OD and funding. The Federation's own crisis appears reflected in a considerable degree of structural insecurity at the Secretariat.

- Added value of regional RC networks and technical regional resource persons was generally uncontested, especially in (sub-) regions that present a certain degree of contextual homogeneity.

- Strategy 2010 has made a huge difference to H\&C activities of the NSs consulted; the two most commonly observed effects were 1) it helped to focus activities from a "too thinly spread" mix of activities towards 3-5 core H\&C businesses; 2) it strengthened community-based activities, situated 'upstream' in the public health model.

- Among the comparative advantages of 'RC-ness' mentioned mainly by RC members themselves, salient ones are: 1 . being indigenous, recognised and having good links to the authorities; 2. being part of an international RC Movement, 3. working through volunteers, close to the community and everywhere 4 . being able to unite people of different origins and strata, and 5. financial transparency, accountability and a proven track record.

- In the countries visited, anecdotal evidence was found that the RC had generally a good public image and that media interest was on the increase. Often, however, the $\mathrm{RC}$ may still be known more for its disaster response than for its day-to-day $\mathrm{H} \& \mathrm{C}$ activities.

- A high degree of donor- and project dependency was observed. Direct or indirect state support to NSs varies between countries; so does income through (often 'traditional' $\mathrm{H} \& \mathrm{C}$ ) activities or endowments. While internal RC funding is still easier to come by, the portion of external funds appears to be on the rise.

- A national disaster - alternatively, big public campaigns - can allow a NS to perform a quantum leap through investment in OD and capitalising on a good track record. Many NS may not be using fully their potential to raise funds, especially locally and with non-Movement donors.

- Accountability mechanisms, beyond reporting to various donors, include project evaluations, internal and external financial audits, audits commissioned by PNSs and other donors and, financial transparency: the publication of balance sheet and income / expenditure statement in the yearly public reports appears to be standard procedure.

- Some NSs are in a comfortable situation with regard to their own H\&C structure, but stability may still be minimal as long as core staff is paid through project funds; other NSs do not have sufficient capacity for own $\mathrm{H} \& \mathrm{C}$ policy making and programming.

- H\&C staff present, however, were involved in various kinds of training and capacity building, health-related or in management and programming. Core staff reported a rather high degree of satisfaction with regard to possibilities for continuous training.

- Retaining volunteers is more difficult than recruiting them; special efforts need to be directed at young volunteers. The range of volunteer work observed was very wide.

- NSs give various kinds of incentives to their volunteers. Indispensable are regular monitoring and supervision, periodic feedback meetings, continuous training and other support. The degree to which volunteers are represented in the NS structure varies.

And the main recommendations: 
- The Federation should continue to evolve in the direction of being less of an implementer, but fulfilling a co-ordinating, facilitating, networking and capacity building role (the present Tsunami-related fundraising success in disaster-relief is a test in case).

- The strategic 'outsourcing' of Resource Centres for specific know-how (psychological support, First Aid) may be a path to follow, providing the necessary services where the know-how is already available.

- In (sub-)regions that are not contextually homogenous enough or do not consist of 'natural allies', the Federation should attempt to increase effectiveness of the (sub-) region or step up other support to NSs in order to compensate for regional shortfalls.

- The Federation should make all efforts possible to invest in the NSs' capacities to create and 'sell' H\&C projects, especially at national level and with non-Movement donors. Strengthening managerial and technical H\&C core capacities at HQ and branch level - a precondition to scaling-up - must be OD priority.

- Considering their importance for the work performed, community volunteers should be represented in the national board of a NS and in its executive council. NSs should make volunteer management a cornerstone of OD. Secretariat and/or the Regions should consider doting themselves with a small volunteer support unit.

\subsection{Working together effectively}

The main conclusions were:

- International and regional co-operation with UN and other international organisations appear to be actively sought and have borne fruit in a number of instances.

- The relative weight and remaining potential of forming national or regional consortia could not be assessed, but anecdotal evidence was given that working in a consortium can decrease the dependency from isolated Federation appeals.

- Numerous and varied were multilateral and bilateral partnerships observed and reported at country level An easily neglected partner is the ICRC, which can give significant support to a NS, when present.

- Sharing of findings and operational know-how was observed in a number of cases, even adoption of RC know-how by the MoH. Very common or probably the rule is membership by the NS in health-related national or regional committees.

- Although anecdotal evidence points at an increase of non-Movement partnerships, in the meantime, the 30 or so PNSs working with poorer NSs are "like oxygen for the blood" for many of these. A clear trend over time to improvement of relationships between PNSs and NSs was found, as a result of a mutual learning process.

- Preferences between bilateral and multilateral work among PNSs vary widely, so do criteria used by PNS for choosing partner countries. With regard to the field of work, PNSs tend to export their own know-how. No recipe has been found how to handle 'basket cases' of NS, the ones that have an integrity problem, for example; the Federation is thought to have to play the most important role.

- The expression of the subsidiary role to the government varies between countries; but close co-operation with the $\mathrm{MoH}$ appears to be the rule.

- Closer to the ground, NSs work with an even wider range of government and civil society organisations: NGOs, UN organisations, the local MoH or whole networks of local stakeholders. Partnerships with the private sector were less frequently observed.

And the main recommendations: 
- The Federation and the regions should continue to actively co-operate with relevant UN and other international organisations.

- The idea is to be pursued to create an additional profile of Federation delegate, whose main skills and task would be regional fundraising, especially through forming consortia.

- The Federation should increase its efforts to support NSs in developing effective partnerships.

- The bottom line for PNS programmes and project must be that they fit into the strategic plan of the NS, which must have the last say. PNSs should reinforce the trend away from being actors towards the development of the NS through mid- to long-term partnerships for programmes that include OD components.

- The administrative overload of responding to different PNS requirements is to be alleviated by introducing common administrative procedures for one NS.

- NSs should increase efforts to co-operate with universities: for evaluations and needs assessments, including students in RC activities or for university staff to lecture in seminars.

The main lessons learnt:

- Short-term projects, though not necessarily, are liable to do more harm than good.

\subsection{HIV/AIDS and other health priorities, 'traditional' activities, Water and Sanitation, and ethical issues.}

The main conclusions were:

- Incorporating HIV/AIDS in permanent health programmes has become near universal. Prevention and lending the RC name to advocacy are the most common activities. Fight against stigma and discrimination is still relatively new for some NSs. A range of other activities were observed: Voluntary Counselling and Testing, working with orphans, home-based care, access to anti-retroviral therapy, and Harm Reduction.

- Progress made by NSs in empowering PLWHA in the fight against HIV/AIDS varies between close mutual co-operation and visible institutional solidarity and timid individual co-operation only, if at all. On the other hand, the number and kind of general partnerships formed by NSs in the fight against HIV/AIDS is impressive.

- The main limiting factor for the scope of work with HIV/AIDS is limited funding; some NSs implement only programmes supported by PNSs.

- NSs engage in a wide range of other health priorities according to national needs; some, however, are severely limited in doing so by their funding situation.

- A number of 'traditional' activities are completely outdated in the sense that they do not serve the most vulnerable. Many NSs have already handed them over to the MoH. Unease exists e.g. about curative care activities; some NSs treat them as separate, purely income-generating entities.

- First Aid occupies a privileged place among traditional activities owing to its multiple functions. While there is disparity between the discouraging Federation discourse on $\mathrm{RC}$ involvement in blood banks and the globally high portion of blood products manufactured by NSs, the attitude of the Federation and NSs towards promotion of voluntary, non-remunerated blood donation is unambiguously supportive.

- The Federation plans to increase its engagement in the field of Water and Sanitation, and to increase the share of developmental projects. 'Software' aspects are to gain importance in relation to hardware; sustainability is to be stressed. Anecdotal evidence was found that the latter considerations are already being made. 
- A branch manager mentioned the constant danger that the $\mathrm{RC}$ would "change from an idea into a firm". In some of the ethical issues flagged up, the power of humanity, or its limits, sometimes becomes more visible again.

And the main recommendations:

- The Federation is to continue its efforts to encourage and support all NSs to play a significant role in HIV/ AIDS response, through internal advocacy, capacity building and facilitating access to funds (e.g. the GFATM). Care must be taken that no aspects relevant for a given country are neglected.

- Where PLWHA are 'invisible', this should trigger an increased effort to fight against stigma and discrimination. A NS may also play an important role in helping PLWHA to get organised.

- The Federation and NSs should take care not to neglect national health priorities other than HIV/AIDS - without, however, spreading resources too thinly.

- To conduct an in-depth evaluation of 'traditional' activities, with specific focus on the ones with which many NSs are not quite at ease: curative health care and nursing schools, professional ambulance services and blood banks.

Main Lesson learnt:

- As an integral part of civil society, the RC itself is not immune to organisational fears and residual stigma and discrimination with regard to PLWHA. 


\section{INTRODUCTION}

The Federation has called unequal access to health "the Solferino of our time" [reference 1 in annex C]. Health \& Care programmes represent the biggest and a growing [2] part within the activities of National Societies (NSs) and the Federation: more than 50\% for the latter (including the Health \& Care part of emergency response ${ }^{1}$ ), and in the NSs visited, between 60 and $80 \%$. This thematic review of the area of Health \& Care in the Community (H\&C) forms part of the ongoing mid-term review of Strategy 2010; its aim is to learn from implementation experience. The primary client for this review is the General Assembly and the Governing Board of the Federation. More on the background and details can be found in annexes A (Terms of Reference) and B (Inception Report). The structure of the report follows the one proposed in the Review Approach Paper [3]: 1) responsive and focused, 2) the well functioning National Society and 3) working together effectively; for each topic it looks at a) the global/regional, b) country and c) operational level.

\section{METHOD}

The review initiated with desk study and interviews at the Secretariat and was complemented throughout with (mainly internal) literature study (see annex C). Five National Societies were visited (in Nigeria, Honduras, Kazakhstan, Namibia, and Norway; see annex D); the first three visits included peer reviewers, who also completed the picture from their own societies' view. The first visit, to Nigeria, by an external consultant and a peer reviewer, lasted four days. The team leader for the other visits, also an external consultant, spent altogether 14.5 days in the field, to which cumulative 9 days of the three peer reviewers are to be added. The bulk of the investigation consisted in semi-structured interviews with key informants, group interviews with community members or volunteers, often combined with site visits and direct observation. Eight telephone interviews were conducted by the peer reviewer in Almaty with branch managers of the Kazakhstan RC and by the team leader from home to presidents or health co-ordinators of RC Societies (ten of a total of 35 proposed contacts and an additional one could be reached). The detailed interview guide was also sent out by electronic mail as a questionnaire to over 30 potential respondents of RC Societies; one was filled and returned. In Kazakhstan, the peer reviewer functioned effectively as a translator through half of the field trip, until professional help was found; in Namibia, peer translators were used in the few instances where this was necessary.

The review was fraught throughout with operational and methodological difficulties: 1. lack of lead-time (owing to change of team leader after inception); 2. too small a sample (MENA was not even represented, not even in phone interviews) 3. extremely strong sampling bias (according to Federation respondents, the NSs visited were always "(one of) the best in the region"; 4. short field trips (3.5 days per country) that allowed for rare, short and far from random ventures out of the capital city and for very limited time for branches, partners, other stakeholders, beneficiaries, let alone the affected population; 5. repeated periods of standby during the review in which time and momentum was lost, and repeated change of plans owing to internal and external constraints; 6. absence of key respondents (in Kazakhstan, international organisations had already left for Christmas, the NS was out of Almaty in a national meeting, and the $\mathrm{MoH}$ unavailable; in Nigeria, the $\mathrm{MoH}$ and UN organisations were unavailable owing to a national immunisation campaign and Namibia was basically closed for

\footnotetext{
${ }^{1}$ A sometimes significant part of emergency response work is Health-related - of the Federation and National Societies, e.g. of the Norwegian RC who spends a large part of its budget abroad.
} 
summer holidays); 7. the peer reviewers, when available, were last-minute choices with no lead-time either (with possible exception of the first); 8. the short duration of this ambitious review precluded working more in-depth with issues such as common performance indicators; 9. Key respondents from within the Federation (e.g. the Health Commission, with one exception) were not available for interviews.

\section{Conclusion}

Owing to its serious methodological limitations (especially the small and biased sample and the small number of external respondents), the results presented are at best a 'snapshot review' with little claim to wider relevance. It can be hoped, however, that the review contributes to guide a final in-depth H\&C evaluation of Strategy 2010.

\section{Recommendation}

For any follow-up review, the Federation should strive to achieve a representative sampling that includes possibly more NSs from all regions, and also the weaker ones. In order to enhance the learning effect, the inclusion of a peer reviewer of the Federation or the Secretariat is to be considered.

\section{Lesson learnt}

The operational difficulties this review faced are liable to reflect to a certain degree the difficulties faced by the Federation in its work as a membership organisation. Also, it proved often difficult if not impossible to separate $\mathrm{H} \& \mathrm{C}$ issues from wider organisational and structural issues, such as fundraising capacity.

\section{FINDINGS AND DISCUSSION}

\subsection{Responsive and focused}

\subsubsection{Global/regional level}

\subsubsection{Millennium Development Goals and client outcomes}

Strategy 2010 is supposed to contribute to all Millennium Development Goals (MDGs) [4]. The MDGs more specifically related to Health \& Care in the Community (H\&C) are:

4) Reduce child mortality

5) Improve maternal health

6) Combat HIV/AIDS, malaria, and other diseases,

7) Ensure environmental stability

To a lesser degree, however, H\&C activities contribute also to other MDGs, such as 1) eradicate extreme poverty and hunger and 2) achieve universal primary education. ARCHI 2010, for instance, mentions poverty specifically as a focal area [4]; an example for the latter is the effort of the Namibian RC to enable Orphans and Vulnerable Children (OVCs) to enrol in primary school by providing school uniforms, stationary and negotiating a waiver of school fees in Namibia. The Federation's recommendation to work in "complementarity with the $\mathrm{MoH}$, especially outreach and prevention" [4] is being followed exemplarily, such as in the community-based primary health care programme of the Philippine RC, or in Namibia, where the home-based care RC volunteers start working with their (mostly AIDS-) patients in the 
hospital prior to their release and later, are supplied with dressing material from peripheral MoH clinics.

Whereas all $\mathrm{H} \& \mathrm{C}$ activities observed were found to contribute to one or more of the MDGs, not every National Society (NS), obviously, has activities contributing to all MDGs (see chapter 4.1.2.2. on relevance). The scope for action within the MDG framework, with exception for a few rich NSs in rich countries, remains therefore almost unlimited.

The MDGs were never referred to explicitly during the field visits; their actual importance for policy-making remains therefore difficult to gauge. However, visibility of the RC contributions is limited: some NSs get less credit for permanent low-key activities than for, say, disaster relief; also, quantifying the contribution remains difficult if it is not explicitly related to the magnitude of the problem. The Kazakhstan RC, for instance has 192 permanent clients in its Harm Reduction programme; the Namibia RC in 2003 ran a project for 80 OVCs in Kavango Region [5]. Without additional information or research, it is impossible to know whether these two programmes represent a drop in the ocean or a sizeable contribution. The number of branches that have implemented a certain activity can be a rough indicator.

Has the collective progress towards Strategy 2010 been demonstrated in terms of client outcomes? In addition to the comment made just above (that the $\mathrm{RC}$ contribution to the total size of the problem is often unknown), it must be stated that actual outcome or impact is rarely monitored or evaluated; most Monitoring and Evaluation focuses on input, process or output indicators (see also chapter 4.1.2.4. on planning). Examples of good practise for outcome indicators are: knowledge gain, measuring e.g. pre-and post training knowledge about HIV/AIDS, or TB cure rate among client patients (both Kazakh RC). Good practise for measuring impact indicators (provided the assumption of significant RC contribution is justified): regional TB incidence and prevalence (Kazakh RC), police record of violent incidents pre-and post a 'Stop Violence' campaign of the Norwegian RC, and decrease of HIV prevalence observed by 585 per year in cities with needle and syringe exchange, vs. an increase in control cities of $6 \% / y[6]$.

\subsubsection{Making Strategy 2010 operational}

A Secretariat official described the text on H\&C in the Strategy 2010 document [7] as a "declaration of intention". By definition, such a declaration needs to be spelled out as a policy with strategic options. This has in some cases been done by continent, such as through ARCHI 2010 [18], the Ouagadougou Declaration [13] and Equidad y Salud en América [20]). ARCHI, for instance, was mentioned as the most important policy document by the Ugandan $\mathrm{RC}$, upon which the national strategic plan was then based. Other strategic plans are regional, such as the Plan de Acción América Latina y el Caribe [21], or in Central Asia, where a regional strategy was developed and then adapted by each of the five NSs. A regional consultation process is also reported to be currently under way in Bangkok for designing a regional strategic plan. In countries where no regional policy formulation exists (or preceding it), Strategy 2010 has either been actively translated into policy and strategic options for branches (Norwegian RC) or incorporated when devising strategies (Philippine RC, Argentinean RC). In Europe, various subgroups and meetings were considered of vital importance, such as the Stockholm Group and ERNA. No translation into a regional strategic or action plan was reported from Oceania. 


\section{Conclusions}

Although the MDGs were never referred to explicitly during the field visits, the H\&C activities observed all contribute to achieve the health-related ones. With the exception of rich NSs in rich countries, however, plenty of scope remains to contribute in 'neglected' areas such as improving maternal health.

Strategy 2010 needs an active 'translation' into policy and a strategic framework. According to the degree of homogeneity and the means available, this can be - and has been - done by continent, region or country. Alternatively, a minimalist version is integration into individual country strategies.

\section{Recommendations}

Visibility of RC contributions to the MDGs is to be enhanced by indicating its magnitude compared to the size of the problem; moreover, significantly more efforts must be made to measure and demonstrate outcome and impact.

The Federation should make sure that every NS has access to a (sub-) regional or local 'translation' of Strategy 2010 into a H\&C policy and a strategic framework adapted to (sub-) regional or local context.

\subsubsection{Country level}

\subsubsection{Beyond disaster victims to 'structural vulnerability'}

Arguably the most profound change for H\&C in Strategy 2010 was the shift beyond victims of an individual or collective disaster toward target groups that are 'structurally vulnerable'. For the NSs visited and consulted, this shift has had a huge impact. Almost universal is the inclusion of HIV/AIDS-related activities beyond prevention (see chapter 4.4.1. on HIV/ AIDS). Among other examples are:

- The NS in El Salvador added community health to traditional activities (ambulances, blood bank);

- When the NS in Argentina devised H\&C strategies as a response to the consequences of the economical crisis in 2001, nutrition / food security and poverty-related diseases were added, in addition to HIV/AIDS-related activities;

- The NS in Honduras conducted an internal campaign for acceptance of PLWHA as $\mathrm{RC}$ clients;

- Changing the focus helped the NS in Namibia to get rid of activities that it did not consider as core business, such as home care for middle class people;

- The NS in Kazakhstan has added the national health priorities TB and HIV to the traditional running of RC hospitals and clinics;

- The NS in the Philippines maintains a strong focus on public health in disasters; although it did target the structurally vulnerable before (they are also disasters-prone), it has since adopted a more pro-active, community-based stance.

In countries with a strong tradition of RC disaster management, this shift has been described as "complicated" owing to deep-rooted internal and external perception. The news focus on the community requires quite a different profile of volunteer for the NS in Colombia; in El Salvador, fears were even voiced within the NS that it was about to lose its identity. Another factor that can slow down the opening towards these new clients is simply the lack of means 
for a small NS that cannot count on significant enough investment from the Federation and/or PNSs. On the other hand, exceptionally, activities for 'structurally vulnerable' preceded - and probably influenced - strategy 2010, such as the then revolutionary Harm Reduction programme of the Italian RC, of the work of the Danish RC with Asylum seekers.

Who are the 'structurally vulnerable? As a general definition, formulations such as "exposed to a situation beyond the coping capacity of one individual" are helpful. More specific definitions of vulnerability vary between continents; within regions though, there appears to be a high degree of congruence. The most common denominator is poverty, with its many known consequences on health, among them: limited access to health care, limited education impairing effective health-seeking behaviour, lack of access to safe drinking water and sanitation, nutritional deficit and especially for girls, early marriage or dangerous survival strategies. Furthermore, the following groups have been defined and targeted as vulnerable ${ }^{2}$ :

- the poor

- PLWHA and their families

- street children

- ethnic, marginalized minorities

- the long-term displaced (by natural or man-made disaster)

- the elderly

- the unemployed

- the homeless

- prisoners

- $\quad$ single-headed households; families with numerous children

- the chronically ill, mentally ill, and handicapped

- migrants (returnees, refugees)

- substance abusers

- the lonely

- victims of violence

- persons in social rehabilitation (ex convicts, ex substance abusers)

- people who are not able to use available state health and social services

- children of imprisoned parents or children of other 'problem households'

Many of these identified target groups accumulate two or more conditions, of course: the elderly, lonely and chronically ill or the household headed by a single, substance-abusing mother. Specific vulnerabilities include, with regard to HIV/AIDS: youth, commercial sex workers, men having sex with men, truck drivers, soldiers and intravenous drug users; with regard to TB: prisoners and again the poor, owing to overcrowding, lack of heating, nutritional deficit, lack of access to care and lack of knowledge that influences positively the care-seeking behaviour.

The importance of poverty justifies the ongoing debate within the Federation of its realistic possibilities to contribute significantly to the first MDG: poverty reduction. In Armenia, 60\% of population is officially poor; in Nigeria, $70 \%$ of the population live on less than 1 USD per day, in Namibia, $34 \%$ and $60 \%$ on less than 1 USD per day.

Three concluding remarks are warranted with regard to vulnerability. First, within every country a shift over time can be observed, accompanying economic and social progress: the

\footnotetext{
${ }^{2}$ the examples, roughly from top to bottom, are representing examples taken from to developing to developed countries
} 
handicapped in Norway, for instance, were once in need of RC assistance but not anymore, having organised themselves as a vocal, efficient group. Secondly, the difference between the extremes of the 'most vulnerable' is striking: whereas, for instance, we hear from Nigeria that there is a "high poverty level in the community" and that there are "too many needs of the vulnerable", the Norwegian RC has identified a subgroup of clients who are children of parents who were both convicted and one of them is freed, but prohibited by law to visit a prison and therefore, from taking the children to see the parent still serving term. Lastly, the most vulnerable accumulate the biggest share of the burden of disease and are most difficult to reach. Again, difficulties present themselves differently, implying the cost of logistics in the desert or in Oceania or the cost of going with a very fine comb through an affluent society.

\subsubsection{Relevance of $\mathrm{H \& C}$ activities}

H\&C activities observed and reported (with the possible exception of some 'traditional' activities, see chapter 4.4.3.) generally appear to be relevant to the most important stakeholders: the beneficiaries, the $\mathrm{MoH}$ and the RC itself. Examples of very clear RC contribution to national health priorities are community-based integrated PHC in the Philippines (including Water and Sanitation), the targeting of poverty-related diseases (dengue, Chagas, TB) in Argentina, of TB and HIV/AIDS in Kazakhstan, working with Youth in poor urban neighbourhoods (Honduran RC) or, as in numerous countries, participation in EPI campaigns through community mobilisation. Often, direct clues are taken from the authorities, such as epidemiological data in El Salvador or social priorities in Norway. The latter is an interesting - and extreme - case of a country where the state is able to provide preventive and curative health care, which leaves, apart from HIV/AIDS prevention, only part of the social burden and international health to the Norwegian $\mathrm{RC}$, whose volunteers visit the lonely and the prisoners, for instance.

A side-effect of the broadening of the spectrum of $\mathrm{H} \& \mathrm{C}$ activities under the influence of Strategy 2010 are raised expectations: by the MoH, the public or NGOs (reported e.g. from The Fiji and Kazakhstan RC). Misperception, i.e. confusing local track record and international brand name with availability of funds, often leaves no alternative to a NS than to disappoint some expectations, for example of NGOs that hope to tap into RC funds. On the other hand, the policy dialogue of some NSs may even allow influencing, directly or indirectly, public sector policy and programs in core areas. The NS in El Salvador, for instance, contributed to a pre-project of law that protects breastfeeding mothers, and the NS in Honduras influenced national blood transfusion policy in the direction of banning export of blood products.

If most or all $\mathrm{H} \& \mathrm{C}$ activities are relevant, this does not mean that the NSs are tackling all relevant issues - although the close and good relationship generally observed and reported with the MoH should guarantee that NS H\&C activities do not completely miss out on a national health priority. A lot of what is not done, but relevant, concerns activities complementary to current ones. The magnitude of the HIV/AIDS problem (in one area visited, $43 \%$ of the population is reported sero-positive) and the availability of funds have allowed the Namibian RC, for instance, to mount an impressive anti-HIV/AIDS programme including all three 'pillars', There is awareness, however, that the network of volunteers may, ideally, be engaged in a more comprehensive community approach. The NS in

\footnotetext{
${ }^{3}$ Prevention, fight against stigma and discrimination, therapy
} 
Honduras, with the help of PNSs (Swiss and Spanish RC) have resettled vulnerable families post-Mitch in new a settlement. The RC community volunteers themselves mentioned that they would like to include the protection of the surrounding forests into their activities. Other useful - arguably, necessary - 'complements' would be the inclusion of food parcels for TB patients in Kazakhstan (as part of the treatment) or work, in Namibia, on gender role, to which a large part of the plight of women clients can be attributed.

Other activities, though recognised as priorities by the NSs, are simply not tackled, such as substance abuse in Honduras, work with prisoners in Kazakhstan (plans exist, though), or health promotion in Armenia, especially MCH-related. In most of these cases, the NS is probably aware of the danger of spreading too thinly.

\subsubsection{Operational choices}

Beyond the fit with the RC mandate, health and social needs alone would ideally be the second determinant for operational choices. Limits of financial and/or human resources, usually interfere significantly in the decision-making process, and sometimes also pressure from outside. To start with the latter, examples were related of an NS successfully resisting a "useless" project proposed by a PNS in 'their' territory; on the other hand, even a rich and powerful PNS could not resist the offer by its own Foreign Ministry to implement a project with the $\mathrm{MoH}$ - and not the host NS - in a country that in turn had put a request to the donor government. While very few examples of ceding - or not - to pressure were related, much more common was what one peer reviewer called "dancing to the sound of what comes in..." While the existence of needs appeared always to be a prerequisite for an operational choice, availability of funds were mentioned to be se second, if not foremost important factor. Among programmes that were spontaneously considered to be easier to fund were:

- TB, HIV and other major killer diseases

- (health-related) disaster relief ${ }^{4}$

- programmes with tangible results, e.g. WatSan

- Programmes for immigrants and mental health (in a rich country)

Considered more difficult to fund were (not surprisingly, the second list is longer than the first):

- Organisational Development (OD) and capacity building

- administrative costs

- programmes for structural/financial stability at the Secretariat.

- community health, unless tangible result (e.g. immunisation coverage)

- programmes with intangible results, e.g. health promotion

- safe motherhood

- food security

- long-term developmental projects

At a first glance, this simply looks like 'relief' still priming over 'development'; it does, to an extent. However, for food security as a point in case, the opposite may be true: donors do not like it because they do not consider it sustainable. Were it considered an investment into the health of an individual person, however, the argument may cut the other way round. Along

\footnotetext{
${ }^{4}$ especially with a significant Diaspora residing in a donor country
} 
the same line, one NS reported that donors appear increasingly willing to invest in capacity building.

Resources are not always available for formal needs assessments, but some NSs have conducted them, even repeatedly. A top-of-the-range example - not affordable by everyone is the Norwegian study and publication 'Social Pulse' [8], which identifies the vulnerable groups within an affluent society. But also less affluent NSs have manage to undertake own needs assessments, or used secondary data, such as the local Human Development Index in order to identify target areas, as the Namibia RC did.

The inclusion of other relevant stakeholders for $\mathrm{H} \& \mathrm{C}$ programme planning was found to be common practice. The Honduran RC works in its branches through local networks that include the $\mathrm{MoH}$ and other organs of civil society; PAHO is generally consulted in Central America; in many countries beneficiaries take part in the decision-making process being volunteers themselves: truck drivers who distribute condoms to colleagues or PLWHA working in Youth prevention. The RC in Argentina arrived at its recently established strategic plan through a wide-reaching consultation process involving as specialists 'volunteerconsultants', The Sierra Leone RC includes Traditional Birth Attendants as resource persons in its women's groups and in the branch visited of the Namibia RC, a traditional healer was member of the branch board.

"As much can be achieved through mobilising people and influencing decision-makers... as through delivering services" [7]. Backed-up by its well-known and usually well-respected brand name plus - in the case of the NSs visited - a solid national track record, the RC throws in its weight for advocacy: HIV/AIDS prevention campaigns (e.g. by the Namibia RC), campaigns against violence ('Stop Violence!' by the Norwegian RC), or running a competition on local TV for the best contribution on TB (Kazakhstan RC). A complete list of advocacy activities would fill pages; the point to make here is that advocacy is on safest grounds if linked to and backed up with service delivery: home-based care programmes and night patrols, for the above mentioned.

\subsubsection{Planning process}

No strategic H\&C plan with objectives for the year 2010 was found; NSs follow their own 3-5 year cycle of planning into which the Strategy 2010 has been incorporated in regional or country documents as a still ongoing process. Formal and structured planning (logframe-like) is usually applied for each project in partnerships with PNSs; some NSs, however, have no own over-all H\&C plan.

Though programmes observed appeared generally focused and impact-oriented, baseline data were not systematically collected or, even if collected, used: "we collect baseline data we can't use". Also, formal and/or external evaluations appeared to be rare (such as on the TB programme of the Kazakhstan RC), again apart from the ones conducted by one or the other PNS (and rich NS at home). Indicators used for monitoring and evaluation consist for the most part in input, process and output indicators (e.g. syringes distributed, training courses given, clients visited, respectively). Outcome and impact indicators (admittedly much more difficult to come by) are rare and far between. Anecdotal evidence of progress made in this sense is encouraging, such as the increased use of MoH epidemiological data by the NS of El Salvador, pre-and post project KAP survey by the Swiss and Honduran RC, the observed increase in participation, by prisoners visited by Norwegian RC volunteers, in education and 
social activities and the impact indicators mentioned above (in chapter 4.1.1.1. on MDGs). For any impact measurement (e.g. teenage pregnancy rates in a region of Namibia), the attribution must be based on legitimate assumption of significant RC contribution among others. Innovative approaches to evaluation include, in Kazakhstan, self-evaluation by home visiting nurses, which are then discussed yearly with the supervisor and through a HQ commission.

Some NSs, like the Honduran, Sierra Leone and Namibia RC, express an explicit wish for more structured monitoring and evaluation capacity; many others would profit as well, especially for all own activities not implemented with the help of a PNS.

The degree of (de)centralisation of planning - apart from the political will to decentralise, or not, - depends on planning capacities at branch level. While the latter, in the case of the Nigerian RC, was recommended to be strengthened, the Norwegian RC asked the branches to analyse local needs and devise a local strategy, with district and national help if need be.

\section{Conclusions}

The implementation of the very profound shift recommended by Strategy 2010 - beyond the traditional RC client as a disaster victim to people who are structurally vulnerable - can be hindered by external and internal perception and lack of financial means. All NSs consulted, however, have made and are making considerable progress in this regard. There are indicators, though, that in European NSs, the direction of influence was at least in part the other way round: from the NS to Strategy 2010; this points at the responsibility of all NSs to continue contributing to policy formulation at Federation level.

The task of defining who is most vulnerable is - correctly - being done at (sub-) regional or country level; the vulnerable groups also change over time within a given context, accompanying social and economic development. The loose definition of the Federation, however, fits all. The most vulnerable are difficult to reach; the cost to do so may be incurred through expenses with logistics or, at the other extreme, with an extremely detailed social needs assessment.

$\mathrm{H} \& \mathrm{C}$ activities were found relevant to the beneficiaries, the $\mathrm{MoH}$ and the $\mathrm{RC}$. The generally close and good relationship with the MoH observed and reported should guarantee that H\&C activities continue to be in line with national health priorities, according to the capacity of NSs. NS policy dialogue may even allow influencing public sector policy and programs in core areas.

For the making of operational choices, the existence of verified needs (that also fall within the $\mathrm{RC}$ mandate) is a prerequisite. While the influence of external pressure was found rare, the availability of funding was found to be all-important: often, implementation takes only place where a PNS can be found. As for donors' preferences, at a superficial glance, 'relief' activities still appear to prime over 'development' activities, though with exceptions, e.g. for globally recognised pandemics and by development-conscious donors.

The inclusion of other stakeholders for $\mathrm{H} \& \mathrm{C}$ programme planning was found to be common practice, be it beneficiaries (often volunteers themselves), local organs of civil society, the $\mathrm{MoH}$ at all levels or UN organisations. 
Advocacy activities (of good quality) with regard to health and social welfare are conducted at sometimes impressive scale, for the general and specific publics. It can be argued that advocacy is on safer ground when supported by service delivery - which appears mostly the case.

The degree of (de)centralisation of planning - apart from the political will to decentralise, or not, - depends on planning capacities at branch level

\section{Recommendations}

The Federation should continue enabling the NSs (and vice versa) to be the vanguard of civil society: acting in the community where the state cannot act, or not yet.

A NS may not be able to tackle all health problems in a given country. However, within a given programmes and activities, efforts should be made to act as inclusively and holistically as possible: food assistance can be added to TB home visits, environmental protection to community health etc. A special caveat is indicated not to overlook other priorities in comparison to HIV/AIDS, where money flows easiest at present.

NSs should increase - with the help of the Federation - efforts to measure, beyond input, process and output indicators, also outcome and impact indicators (attribution for impact must be based on legitimate assumption of significant RC contribution). Many NSs should and want to strengthen their monitoring and evaluation capacity, especially for all own activities that are not implemented with the help of a PNS.

\section{Lesson learnt}

If periodic re-assessment of vulnerabilities in society and of the state's capacity to overcome them are not undertaken, a NS risks being stuck with activities that are out-of-date and/or outof-mandate (e.g. private sector curative care).

\subsubsection{Operational level}

\subsubsection{Community / beneficiary involvement and satisfaction}

Field visits were too short to be concluding with regard to beneficiary satisfaction. Anecdotal evidence, however, pointed at a high degree of community and beneficiary involvement. The Kazakhstan RC, for example, piloted the Harm Reduction booklet with clients before publication. The clients were also consulted about what kind of syringes to be given and the volunteers go to great lengths to exchange them, e.g. through mailboxes or home delivery.

In Namibia, a logo and brand name for 'Desert Soul' (a multimedia health, development and communication project) were produced through rigorous community consultation and competition [9]. The Kazakhstan RC also consulted widely with groups of potential volunteers about what kind of incentives would be appreciated by each; the military, for instance, wanted notebooks to write home and got them from the RC, with STD and HIV/AIDS information inside the cover. Another example of including the beneficiaries is the invitation, by the Norwegian $\mathrm{RC}$, of some inmates to the annual prisoner visitor volunteer meeting. A good general indicator that RC action correspond to felt needs is when it follows a request by the community or beneficiaries: in Honduras, the neighbourhood committee approached the $\mathrm{RC}$ for a water and sanitation project (having heard about them from elsewhere) and home-based care volunteers in Namibia are approached by both families and the hospitals to take on new clients. 


\subsubsection{Programme implementation}

Among factors that hindered implementation processes of $\mathrm{H} \& \mathrm{C}$ programmes, lack of funds was probably cited as the most common, as an indicator that neither needs in the population nor the willingness/capacity of the NSs have been covered and exhausted. The high turnover of volunteers was also mentioned more than once (in connection with the limited managerial capacity of the NS to support them), and other factors related to volunteers, e.g. the low rate of literacy, low level of involvement of young volunteers. Attitudes and beliefs can be an external obstacle (in rural Namibia, volunteers were once nearly 'arrested' in a village owing to 'sex talk') or internal ones: the inclusion of new activities and clients recommended by Strategy 2010 have at times requested a special effort within the NS to change minds. An obstacle mentioned once was the lack of a national law that would provide a legal basis to the activities of the NS. Lastly, in Kazakhstan, the lack of traditional heads of communities was mentioned, who could serve as a 'multiplier effect' for dissemination of RC activities and values.

The same multiplier effect was considered to be an important factor that facilitates implementation, e.g. knowledge and skills imparted by the home-based care volunteers, which are then picked up by family members. A general facilitating factor appeared to be the involvement of as many stakeholders as possible from the very start of a programme.

All NSs visited reported to follow $\mathrm{MoH}$ standards in their programmes, or international or regional WHO standards (e.g. PAHO in Central America). With regard to public health in disaster response, the Namibian RC reported the use of Sphere standards during the recent floods in Caprivi.

\section{Conclusions}

Anecdotal evidence pointed at a high degree of community and beneficiary involvement by the respective NS, which is fostered by the way of working itself, i.e. through volunteers that are, after all, part of the community and in some instances, beneficiaries themselves.

When a NS runs into problems, internally or externally, with prevailing attitudes and beliefs, this may be taken as a proxy indicator that it is acting at the forefront of change in civil society. A general facilitating factor for programme implementation appeared to be the involvement of as many stakeholders as possible from the very start of a programme

\subsection{Well-functioning National Society}

\subsubsection{Role of the Federation, the Regions and the Secretariat}

The field where the Federation/Secretariat was reported to have most added value for NSs was at the level of policy formulation and formulation of strategic plans, either directly or through the region, and in facilitating a learning process, capitalising experience and repeating good practice. Regional networks such as the Central American Network (including Mexico and Panamá) that receive Federation support were repeatedly mentioned as a vital forum of exchange and information. In other regions, Federation support for translation was appreciated, such as into Russian, which serves as a common working language for the Central Asian network. In one instance, a peer reviewer was impressed by the difference in support received in the region visited as compared to the home region. 
Technical assistance was often highly appreciated, in the field of HIV/AIDS in Namibia and Moçambique, and in Kazakhstan with regard to TB and capacity building for programming. More than one NS wished for more support in Organisational Development (OD), the Namibia RC, for instance with regard to marketing, resource mobilisation and formalising Monitoring and Evaluation. Although many instances were mentioned where the Federation has been instrumental for fundraising (Philippine and Namibia RC, for instance), many others voiced a certain disappointment with regard to accessing additional funds through the Federation. The Moçambican RC would appreciate Federation assistance with implementing common administrative procedures with its PNSs. Fundraising is less high on the agenda of expectations of PNSs (some, on the contrary, are important contributors), but high-level and effective contacts with relevant UN agencies and the Global Fund to Fight AIDS, TB and Malaria (GFATM) are expected.

The added value of (sub-) regional networks and technical regional resource persons was generally uncontested. Especially in (sub-) regions that are either culturally and historically rather homogenous (Central America more than South America) or share a common colonial language (Central Asia) co-operation with regard to $\mathrm{H} \& \mathrm{C}$ was reported to be very close, including peer evaluations, seminars and regular H\&C meetings. Similar importance of meetings and sharing was also reported from East Africa, West Africa and South-East Asia. Such meetings are an important forum for policy-making and learning experiences: the Namibia RC home-based care programme, for instance, was adapted from a Danish RCsupported model piloted in Zimbabwe, and the Finnish RC adapted the Children's First Aid TV program of the Norwegian RC. (Sub-) regions also allow for economy of scale for common training and foster the building of important personal relationships. RC regional networks were reported to be extremely useful for tackling HIV/AIDS: ERNA (in Europe), or the Southern Africa Regional Network, through which 'Desert Soul' was produced as a highquality regional advocacy product.

The Federation is suffering from a "crisis of leadership and confidence", which is reflected in the Secretariat itself, where the process of downsizing appeared to have provoked a high degree of structural insecurity. Self-critical remarks were made with regard to the lack of a volunteer department (for the world's biggest volunteer organisation), the danger of tailoring the suit according to the cloth available (we can't go into country X, we haven't got the money) and lastly, the wish was expressed for improving analytical power, especially regarding non-linear extrapolation, issues (like HIV/AIDS) that were not business-as-usual and reaction to the unpredictable (e.g. SARS).

Limits are set to the executive power of the Federation as an independent membership organisation that respects diversity: it can act by persuasion only. Its main health policy instrument, the Health Commission, meets once yearly and was reported to be active and competent. Health is also included in the ongoing exercise 'Federation for the Future' [10]. The Federation does not appear to suffer from lack of ideas, but to have difficulties with implementation that are often related to funding shortfalls, which in turn may encourage opportunistic behaviour. It has, however, come a long way from the criticism of the 1990 that it lacked focus and was insufficiently engaged in partnerships.

Lastly, the new phenomenon of 'regionalisation' (vs. concentration at the Secretariat): the Resource Centres for e.g. psychological support in Denmark and for First Aid in France may be a path to follow, providing the necessary services where the know-how is already available while avoiding HQ growth and making due concessions for diversity. 


\section{Conclusions}

The Federation has often lived up to expectations of NSs with regard to policy formulation and technical assistance, especially through the regions that are considered well functioning. Although positive examples of assistance with OD and funding were reported, the Federation often fell short of such expectations, especially with regard to the latter. Linking up with relevant UN organisations at high level is also expected. The Federation's own crisis appears reflected in a considerable degree of structural insecurity at the Secretariat.

The (sub-) regions are potentially very important for $\mathrm{H} \& \mathrm{C}$ activities; added value of regional networks and technical regional resource persons was generally uncontested, especially in (sub-) regions that present a certain degree of contextual homogeneity. Regular meetings are an important forum for policy-making, learning experiences, and present the opportunity of economy of scale for training and the production of regional technical and advocacy material.

\section{Recommendations}

The Federation should continue to evolve in the direction of being less of an implementer, but fulfilling a co-ordinating, facilitating, networking and capacity building role (the present Tsunami-related fundraising success in disaster-relief is a test in case).

The strategic 'outsourcing' of Resource Centres for specific know-how (psychological support, First Aid) may be a path to follow, providing the necessary services where the knowhow is already available.

In (sub-)regions that are not contextually homogenous enough or do not consist of 'natural allies', the Federation should attempt to increase effectiveness of the (sub-)region or step up other support to NSs in order to compensate for regional shortfalls.

\subsubsection{Country level}

\subsubsection{Has Strategy 2010 made a difference?}

Awareness of Strategy 2010 below headquarter level in every NS may not be widespread, according to anecdotal evidence. The Norwegian RC, however, had already integrated Strategy 2010 it into its own strategic planning. Likewise in Nigeria, ARCHI 2010 was found to be the main focus at zone and branch levels. Be it in its original form or 'translation' into national or regional policies, Strategy 2010 has made a huge difference to H\&C activities of the NSs consulted, with the possible exception of a traditionally more inward-looking NS such as the Italian RC. Strategy 2010 had two commonly observed effects:

- it helped to focus activities from a "too thinly spread" mix of activities towards 3-5 core businesses, as stated e.g. by the Ugandan and the Fiji RC.

- it strengthened community-based activities, situated 'upstream' in the public health model $^{5}$, as stated e.g. by the Colombian and Finnish RC.

The latter point is ideally linked with at shift from centrally driven to community-based programming and the former, according to the Norwegian and the Danish RC, "makes work easier for back-donors". The Singapore RC attributes the decision to work with vulnerable

\footnotetext{
5 as opposed to curative, 'downstream' activities
} 
populations across the border in Indonesia to Strategy 2010. The new focus on diseases like HIV/AIDS or TB has had a positive impact on resource flow, e.g. for the Namibia and Kazakhstan RC, respectively. On the other hand, it is certainly true that "2010 does not reflect what is being done": diversity continues thriving among H\&C activities that continue covering a very wide range.

\subsubsection{The difference ' $R C$-ness' can make}

The Federation has decided to determine where the RC has a comparative advantage [1]. Owing to the small sample size, opinions of external respondents could not be collected in sufficient number. The ones collected, however, coincided, with some of the comparative advantages mentioned by RC members themselves, from community volunteers to Presidents, which can be grouped as follows:

- A NS is an indigenous part of the local system, and will stay. Is has a recognised status and good links to the authorities;

- Every NS is part of an international RC Movement with an internationally recognised status;

- The RC works through volunteers, close to the community, everywhere in the country;

- In the RC, people of different religions and different strata of society congregate, respecting the same principles and values;

- Every NS has the chance to be a trustworthy partner owing to financial transparency and accountability as well as a proven track record.

The choice for a donor that sponsors anti-retroviral therapy for PLWHA may therefore fall onto the RC instead of the MoH. Generally, a significant change over time, since 2000, has been the chance to achieve a higher profile in contributing to national health priorities, such as TB and HIV/AIDS. On the other hand, missed opportunities were quoted to 'market' these contributions sufficiently; more than one NS, for instance, was disappointed about not having access to a proportionate share of the Global Fund.

As NSs gain experience and expertise by focusing on fewer $\mathrm{H} \& \mathrm{C}$ activities at community level, they win confidence and do use opportunities to enhance the RC health image. The RC is already a partner in many national health committees (see chapter 4.3.2.1. Working with others); RC professionals also participate in regional and international conferences: the Kazakhstan RC presented its TB program at ERNA. In the countries visited, anecdotal evidence was found that the RC had generally a good public image and that media interest was on the increase. In some instances, however, the RC appeared still known more for its disaster response than for its lower-profile day-to-day H\&C activities.

\subsubsection{Resource mobilisation for $\mathrm{H} \& \mathrm{C}$ programmes}

With the exception of the Norwegian RC, an extremely high degree of donor dependency for $\mathrm{H} \& \mathrm{C}$ activities was observed; commonly, activities were only implemented in branches with a partner - more often than not a PNS. In Kazakhstan, for instance, eight of 18 branches have $\mathrm{H} \& \mathrm{C}$ activities, all with RC Movement support. Also, in Honduras and El Salvador, only branches with PNS support were reported to have a significant level of $\mathrm{H} \& \mathrm{C}$ activities. A peer reviewer confessed to be "tired of implementing short-term boutique-sized projects only" at home. 
Some NSs, however, benefit from direct financial state subsidies for running cost (El Salvador RC) or indirect state contributions, such as the waving of import fees (Honduran $\mathrm{RC}$ ) or a licence for slot machines ${ }^{6}$ (Norwegian RC). The Philippine RC gets state support for health-related disaster management; other NSs don't, e.g. the Namibia RC and Kazakhstan RC. Income-generating activities can contribute to core cost, often through sale of (mostly 'traditional') H\&C services: of blood products in Honduras, First Aid Training in Kazakhstan, health care in Argentina, provision of First Aid during events in Denmark and ambulance rides in some branches of the Norwegian RC (more on these 'traditional' activities in 4.4.3.).

Some NSs carry out local fundraising activities: the Kazakhstan RC branches sell yearly tickets (issued from HQ) of 'member fees' that contribute to core cost and minimal activities, and the Moçambican RC has started a campaign for Firms 'Friends of the RC', which contribute annually. Others, like the Honduran RC, have no staff specialised in fundraising (admittedly, such people are difficult to find in low-income countries); the Namibia RC has just recently hired a communication and fundraising manager who will target the general public and the private industry. Owing to their good public image, many NS have the potential to raise funds locally, as observed for the Nigeria RC.

Internal funds from within the RC Movement were still reported to be easier to come by than external ones. Beyond financing projects and programmes, PNSs, for instance, often invest in infrastructure with a lasting effect. The Namibia RC covers up to $25 \%$ of its core cost through renting out own premises [9] that were originally an endowment by Finnish RC; a branch in Namibia runs an Internet café installed by a PNS and the Swiss RC in Honduras, instead of paying for project staff, invests in branch infrastructure. External funds, however, appear to be gaining in weight; this was often attributed to Strategy 2010 (e.g. by the Argentinean and Ugandan RC) through the widening/change of the H\&C action spectrum. The Harm reduction Programme of the Armenian RC was funded by Soros Foundation, and the Namibia RC covers at present more activities through external than internal RC funds.

Big disasters were in many instances a catalyst for the development of a NS: Mitch in Honduras, the earthquakes in Armenia and El Salvador or the floods in Caprivi. Co-operation with and investment by the RC Movement is a chance to scale up. To achieve sustainability when key staff is all on PNS salary, requires additional efforts well into the post-emergency. With judicial investment in OD, however, a NS can capitalise on a positive track record: 'success sells'; other donors may be easier convinced of the value of investing in a NS. Alternatively, in the absence of disasters, big public health campaigns (polio or measles in West Africa) were quoted to be chances to invest, for instance, in capacity building.

Accountability mechanisms, beyond reporting to donors (PNSs, Federation and externals) include project evaluations (again, mostly commissioned by PNSs), internal and external financial audits, audits commissioned by PNSs and other donors and lastly, financial transparency: the publication of a balance sheet and income and expenditure statement in the yearly public reports appears to be standard procedure.

\subsubsection{Health \& Care Structure in the National Societies}

Some NSs have only very recently created a single H\&C department, like the ones in Honduras and El Salvador - probably another consequence of Strategy 2010. Other NSs have

\footnotetext{
${ }^{6}$ maybe coming to an end, though [11]
} 
consciously chosen not to do so: the Argentinean RC uses of course health professionals in programmes and project, but not as line managers. Certain NSs - especially in large and/or rich countries - appear to be able to afford a substantial core structure at HQ level (e.g. Norwegian and Ugandan RC) that allows for own policy-making, strategic planning and support of activities at branch level. Close co-operation with other departments and crossdepartmental planning (e.g. with Youth) appeared to be the rule rather than the exception in the countries visited and reported on. It appears certain, however, that devising and scaling up health activities will not be possible without significant support to OD, such as reported for the Nigerian RC. This holds especially true for smaller countries or countries with general shortages of health professionals (e.g. Namibia, Fiji), where NSs are struggling at a minimal level with regard to $\mathrm{H} \& \mathrm{C}$ core staff, or below. The Namibia RC just managed to secure a junior health professional that can be groomed to be health co-ordinator, but has at present noone who even could devise a H\&C policy beyond current (HIV/AIDS) projects, for e.g. TB and malaria.

Structural stability is often jeopardised through payment of core staff with project funds, as it is the case in Honduras, Kazakhstan and probably in many other NSs; the Armenian RC keeps losing most of its few health professionals in between projects. High staff turnover was mentioned by one external respondent to be a limiting factor for co-operation with the NS.

H\&C staff present, however, were involved in various kinds of training and capacity building, be it health-related or more generally, in management and programming. Core staff reported a rather high degree of satisfaction with regard to possibilities for continuous training. While there is always a felt need for more (in Armenia for TB-related technical capacities, in Honduras for Monitoring and Evaluation), NSs appeared to go to great lengths in securing training for their core staff; again, mostly through projects, either earmarked or through overheads. A PNS like Norway will always make sure that capacity building and OD is part of any project.

The evaluation was not able to ascertain $\mathrm{H} \& \mathrm{C}$ core capacity at branch level. At best, it appears 'varied', i.e. conditioned by the existence of a project funded at branch level. Some respondents, like the Moçambican RC, mention specifically the wish to strengthen $\mathrm{H} \& \mathrm{C}$ staff in the periphery. Also, the recommendation made for the Nigerian RC, to strengthen branch governance in general, may hold true for other NSs according to anecdotal evidence given. On the other hand, the possibility was reported of that $\mathrm{H} \& \mathrm{C}$ activities contributing to improve the whole NS through well-run operations at branch level that in turn may positively influence governance in $\mathrm{HQ}$.

\section{Conclusions}

Be it in its original form or through 'translation' into national or (sub-) regional policies, Strategy 2010 has made a huge difference to H\&C activities of the NSs consulted; the two most commonly observed effects were 1) it helped to focus activities from a "too thinly spread" mix of activities towards 3-5 core H\&C businesses; 2) it strengthened communitybased activities, situated 'upstream' in the public health model.

Among the comparative advantages of 'RC-ness' mentioned mainly by RC members themselves, salient ones are: 1 . being indigenous, recognised and having good links to the authorities; 2. being part of an international RC Movement, 3. working through volunteers, close to the community and everywhere 4 . being able to unite people of different origins and strata, and 5. financial transparency, accountability and a proven track record. 
In the countries visited, anecdotal evidence was found that the RC had generally a good public image and that media interest was on the increase. Often, however, the RC may still be known more for its disaster response than for its day-to-day $\mathrm{H} \& \mathrm{C}$ activities.

'Projectism' is common: a high degree of donor- and project dependency was observed; often, $\mathrm{H} \& \mathrm{C}$ activities would only be implemented in a branch that has PNS support. Direct or indirect state support to NSs varies between countries; so does income through (often 'traditional' $\mathrm{H} \& \mathrm{C}$ ) activities or endowments. While internal RC funding is still easier to come by, the portion of external funds appears to be on the rise.

A national disaster - alternatively, big public campaigns - can allow a NS to perform a quantum leap through investment in OD and capitalising on a good track record. Many NS may not be using fully their potential to raise funds, especially locally and with nonMovement donors.

Some NSs are in a comfortable situation with regard to their own H\&C structure, but stability may still be minimal as long as core staff is paid through project funds; other NSs do not have sufficient capacity for own $\mathrm{H} \& \mathrm{C}$ policy making and programming. Where core staff is present, the NS governance and management do make considerable efforts to invest in them through capacity building. $\mathrm{H} \& \mathrm{C}$ core capacity of branches level appears varied: in many instances conditioned by the existence of a project funded at branch level

\section{Recommendations}

In areas where a NS is winning sufficient experience and expertise, it should assert its presence in $\mathrm{H} \& \mathrm{C}$ actively at national level, so as not to miss opportunities in competition with more vocal, but not necessarily better performing actors.

The Federation should make all efforts possible to invest in the NSs' capacities to create and 'sell' H\&C projects, especially at national level and with non-Movement donors. Strengthening managerial and technical H\&C core capacities at HQ and branch level - a precondition to scaling-up - must be OD priority for each NS as well as the Federation and supporting PNSs.

\subsubsection{Volunteer work}

The strategy of working through volunteers is a unique chance to unleash the power of humanity for the benefit of the most vulnerable, giving the volunteers themselves the opportunity to add more meaning to life: for a busy person who can be available "every Tuesday evening for two hours", for the unemployed mother in a shantytown or the ex convict who dedicates himself almost full-time to the Harm Reduction programme. The NSs

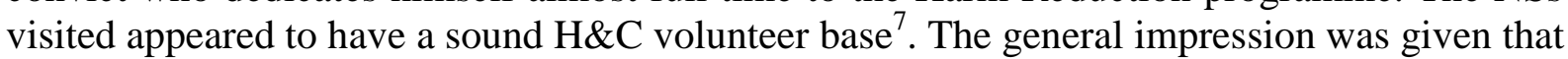
recruiting was less of a problem than retaining volunteers. The Kazakh RC voiced concern about "losing the young volunteers", while the Norwegian RC makes a conscious effort to work with children by publishing a book and TV programme for First Aid for children and Youth, also with the intention of not drying out of volunteers.

\footnotetext{
${ }^{7}$ Namibia reported a number of around 3'500, Moçambique around 3'000
} 
What keeps volunteers going? An interesting case are the three levels of home-based care volunteers in Namibia ${ }^{8}$, where a much higher dropout rate from the level of care givers is reported than from the levels of facilitators and supervisors, which volunteers themselves link to the fact that the former don't benefit from incentives ${ }^{9}$. On the other hand, an external respondent accused the $\mathrm{RC}$ of 'poaching' the $\mathrm{MoH}$ volunteers away with incentives. The $\mathrm{MoH}$ volunteer system, however, without means even for supervision, was found to be a 'virtual' system. Lack of support and monitoring is de-motivating; to retain volunteers, constant investment in them is needed. Among the many incentives mentioned by volunteers themselves that motivate them are:

- To be able to express solidarity: "we are known in the community, and sought after, even at night",

- Recognition by the community: the chance to 'become an important person',

- The opportunity to make own decisions, to grow, to realise something,

- Belonging to the RC, recognised by wearing the emblem, e.g. on a cap or T-shirt,

- Recognition by the RC: thanking letters, memory gifts,

- To be a RC volunteer looks good in the CV,

- The opportunity to learn something useful,

- Restitution of expenses: transport cost,

- Small gifts: a bike for the supervisor that becomes personal property after two years; tools and seeds,

- A supply kit to work with: (e.g. with condoms and ORS),

- Trips to meet other volunteers, regional summer camps for Youth,

- Inclusion in subsidised health insurance,

- The possibility to get a job as an ambulance driver with the government.

Incentives given to and sought by volunteers vary widely. The Kazakhstan RC has conducted an interesting exercise, inquiring with each group of volunteers what would be the most sought-after incentive ${ }^{10}$. Most importantly, though hardly spontaneously mentioned by the volunteers themselves, are regular monitoring and supervision, periodic feedback meetings, continuous training, or facilitating self-help groups, like for prison visiting volunteers (Norwegian RC), if need be, with professional psychological help. In the NSs visited, regular and continuous training appeared to be organised for volunteers.

One RC official said that ideally, volunteers "should not be RC volunteers, but community volunteers". The closest to this ideal would the volunteer who works for his or her community in an integrated way, as it is being tried in Central American Countries and proposed in Southern Africa: a 'community care package' [12] covering all relevant aspect of public health and social welfare for a part of the neighbourhood. Such an approach, however, will not do away with the need for specialised volunteer work, e.g. for Harm Reduction and prison visits.

The Federation has elaborated guidelines with principles of volunteer management, which some NSs have adapted for local purposes: working 6-10 hours per month only, and locally; having the right to supervision and feedback, and receiving small incentives. The Norwegian

\footnotetext{
${ }^{8} 90 \%$ of the home based care volunteers are women

${ }^{9}$ The Namibia RC will probably do away with this difference, which is simply due to shortage of funds

${ }^{10}$ Truck drivers wanted $1^{\text {st }}$ aid kit and condoms; sex-workers: hygiene kits and condoms; Youth: internet cards, stationary and travel cards; the military: notebooks, phone cards and condoms; housewives: food parcels and school stationary for the children.
} 
$\mathrm{RC}$ has even produced general guidelines for volunteers, in co-operation with NGOs and the Ministry of Justice.

Volunteer management is handled by rich NSs though a special department (the Norwegian RC has 30 staff in its Volunteer and Knowledge Sharing Department); poorer NSs manage volunteers by project. The degree to which volunteers are represented in the structure of the NSs varies: in some NSs, volunteer representatives are well represented in e.g. the executive council and national board, in others, less.

\section{Conclusion}

The NSs visited appeared to have a sound basis of volunteers. Retaining them appears to be more difficult than recruiting them; special efforts need to be directed at young volunteers. The range of volunteer work observed was wide: from 'integrated community volunteer' over home-based care for AIDS patients to needle and syringe exchange for substance abusers, and visiting prisoners.

NSs give various kinds of incentives to their volunteers. Indispensable are regular monitoring and supervision, periodic feedback meetings, continuous training and other support. The degree to which volunteers are represented in the structure of the NSs varies.

\section{Recommendation}

Considering their importance for the work performed, community volunteers should be represented in the national board of a NS and in its executive council. NSs should make volunteer management a cornerstone of OD (as recommended by the Ouagadougou Declaration [13]). The Secretariat and/or the Regions should consider doting themselves with a small volunteer support unit.

\section{Lesson learnt}

Retaining volunteers needs a constant effort with regard to supervision, training and other support, which translates into - not negligible - running cost.

\subsection{Working together effectively}

\subsubsection{Global/regional level}

One of the strategic directions of Strategy 2010 is "work[ing] together effectively, through programme cooperation, long-term partnerships and funding, as well as more active advocacy" [7]. The review did not allow for gathering more than anecdotal evidence. Examples for co-operation with UN and other international organisations are the cooperation of the Federation with UNGASS, CDC and Roll Back Malaria (WHO), and of ARCHI with WHO and UNAIDS. The Federation holds observer status in World Health Assembly of WHO [14] and just recently became official member of the STOP TB partnership (WHO) [15]. The MoU between WHO's South-East Asia Regional Office and the Federation [14] is an example for regional co-operation. With regard to sectoral work, a best practise case study on the work on HIV/AIDS of the Federation has been published with UNAIDS and GNP+ [16]. Among new kinds partnerships at global or regional level are the ones (realised or attempted) with multinationals (DHL, Nestlé), the GFATM, Embassies (in Southern Africa), and the World Bank (explored for anti-retroviral therapy since 2003). 
In chapter 4.2.1. (Role of the Federation, the Regions...) we have pointed at a lively exchange within (sub-) regions and given some examples. Another example is the Norwegian 'export' of the 'Stop Violence' campaign to the Netherlands and Bulgarian RC.

Anecdotal evidence was also given that working in a - national or regional - consortium can give access to new - local or regional - funds, thereby decreasing the dependency from isolated Federation appeals. An early example from the 1990 is the consortium, by the German, Swiss and Nordic NSs in Ghana. Contemporary ones are: the mentioned Southern Africa Embassy fund; a consortium between PNSs and the Honduran RC to access EU and UNAIDS funds; GFATM funds given in El Salvador to the RC and a local University; a sixmember consortium in southern Uzbekistan and Tajikistan for maternal, child and reproductive health, as part of which the American RC works with the respective NSs [17]; the consortium in Namibia for HIV/AIDS between the $\mathrm{MoH}$, the RC, NGOs and the private health sector, sponsored by the private industry (Bristol Meyers Squib) and lastly, the consortia of which the Danish RC is part: with other PNSs in West-Africa and with a Danish aid organisation in Ethiopia.

Forming such consortia is a task that requires professional skills (in fact, more than one NS was disappointed about not having had access to a sufficient share of the GFATM). The idea floated in the Secretariat, of a new profile of Federation delegate - without doing away with technical assistance, of course - whose main skills and task would be regional fundraising, was universally acclaimed by respondents (provided the profile can be found: 'speaking the donors' language' and sufficiently imbued with local culture). Partnership meetings were also mentioned as good practice, called by the Federation, but in which the NS sits in driving seat with participation of external and in-country donors.

\section{Conclusions}

International and regional co-operation with $\mathrm{UN}$ and other international organisations appear to be actively sought and have borne fruit in a number of instances.

The relative weight and remaining potential of forming national or regional consortia could not be assessed, but anecdotal evidence was given that working in a consortium can decrease the dependency from isolated Federation appeals.

\section{Recommendation}

The Federation and the regions should continue to actively co-operate with relevant UN and other international organisations.

The idea is to be pursued to create a new profile of Federation delegate - without doing away with technical assistance, of course - whose main skills and task would be regional fundraising, especially through formation of consortia.

\subsubsection{Country level}

\subsubsection{Working with others}

So numerous and varied were multilateral and bilateral partnerships observed and reported at country level that listing them would not be helpful; the most privileged partnerships, with the $\mathrm{MoH}$ and PNSs, are treated separately below. An easily neglected partner is the ICRC, which 
- in times of conflict - can and does give significant support to a NS, as reported from Nigeria and Namibia, for instance.

Sharing of findings and operational know-how was observed in a number of cases, like the provision of community baseline data by the El Salvador RC to the MoH, a IMCI-related 'Health Information System' created by the Honduran RC that is being piloted/adopted by the $\mathrm{MoH}$; the manual for home-based care volunteers written (with Federation delegate support) by the Namibia RC, which is also pending with the $\mathrm{MoH}$ for approval/adoption and lastly, the vulnerability assessment of the Norwegian RC 'Social Pulse', which has been put into the national public domain.

Very common or probably the rule is membership by the NS in national or regional committees, mostly in fields where the own know-how is recognised:

- the Honduran RC forms part, with two NGOs, of an IMCI committee at the MoH,

- the Kazakhstan RC health co-ordinator is member of a MoH TB working committee,

- the Norwegian RC is part of a UN-led forum for Violence and Children,

- the Fiji RC is part of a forum of national Non-State Actors,

- the Namibia RC is part of national and district AIDS coordination committees,

- the Nigeria RC is member of a national working group for immunization,

- a number of RC presidents or SGs form part of the respective GFATM country committee.

These are illustrative examples; most NSs form part of a variety of committees and working groups. One Federation respondent sees an even larger role for the RC: as an umbrella for NGOs, the RC being less specific as an organisation, but having political weight and its Principles \& Values - which needed to be respected! - being nearly all encompassing.

\subsubsection{PNSs}

According to one respondent in the Secretariat, the RC is too consumed with partnerships within the Movement. Anecdotal evidence points at an increase of non-Movement partnerships, such as the Honduran RC working with an AIDS-related US NGO, or the Kazakhstan RC, which will get funds for work with multi-drug resistant TB patients from the private industry (see also chapter 4.2.2.3. above, on Resource mobilisation). In the meantime, however, the 30 or so PNSs working with poorer NSs are "like oxygen for the blood" for many of these.

The trend away from the PNSs and the Federation as actors toward the NSs had been confirmed; one NS colleague called this a shift from 'assistentialism' to the development of the NS. Although some PNSs appear to include a delegate in every project design, others don't where there is no need: no PNS maintains a delegate in Namibia, for example.

A clear trend to improvement of relationships between PNSs and NSs has been reported, probably the result of a mutual learning process (the Sierra Leone RC reported that partnership meetings and common field trips helped). Almost all NSs defined the cooperation at present as very positive, despite frequently mentioned difficulties that needed to be overcome in order to arrive at a common objective and strategy. The bottom line appears to be that the PNS project fits into the strategic plan of the NS, which must have the last say. 
NSs usually contract service agreements with PNSs (and the Federation); financial overheads are used as contributions for core cost and capacity building, or free funds for other activities. The administrative burden can have a positive influence because it imposes financial discipline, but can also lead to an administrative overload with different donor requirements. The Moçambican RC, for instance, is about to negotiate a common Memorandum of Understanding with all its PNSs in order to install common administrative procedures.

The preference of NSs (and some PNSs) is for mid- to long-term partnerships for programmes that include needs assessment and external evaluation and OD components, beyond technical assistance. Short-term projects are liable to more harm than good: one NS had just won the trust of 38 substance abusers in its Harm Reduction project, when funding was stopped; another one raised expectations in a Reproductive Health project, when funding was also stopped after one year only. Offering TB treatment for one year only poses the ethical problem of having to refuse new patients after month six.

Preferences between bilateral and multilateral work among PNSs vary widely and are known: while some are staunch supporters of working through the Federation (and the ICRC), others work exclusively bilaterally ${ }^{11}$ and others again keep bilateral and multilateral work balanced. With regard to the field of activities, PNSs often - and wisely - export their know-how: the Norwegian RC, ambulance services and the Italian RC Harm Reduction. Criteria used by PNS for choosing partner countries vary, too. The Norwegian RC concentrates on conflict and post-conflict countries (which often results also in cooperation with ICRC); the Italian RC prefers historical ties (mare nostrum) and closeness (Eastern Europe and Central Asia); the Singapore RC also works in neighbouring countries; the Danish RC has chosen 14 NSs with which it has established long-term ties (and including OD), the two main criteria being: confirmed needs and the capacity of the NS to tackle them, with some help. No recipe has been found, on the other hand, how to handle 'basket cases' of $\mathrm{NS}^{12}$, the ones that have an integrity problem, for example. Keeping a foot in the door is considered important in order to be able to act once necessary radical changes have taken place, a task for which the Federation is thought to have to play the most important role.

\subsubsection{Relations to the MoH and links with academic institutions}

NSs are subsidiary to their government in all countries; this auxiliary role is stressed in certain countries, such as Italy and Singapore. But also elsewhere, NSs are complementary to the $\mathrm{MoH}$ and work closely with it, bridging the gap between formal service delivery and households [7], taking care that the RC intervention adds to and does not compete with $\mathrm{MoH}$ work [18]. The Kazakhstan RC, for instance, has signed a MoU with the MoH in every region, the $\mathrm{n} \mathrm{RC}$ has agreements with the $\mathrm{MoH}$ for community mobilisation and the provision of blood products, the Norwegian RC maintains national statistics of blood donors and the Argentinean RC performs social monitoring of a government drug supply programme on behalf of the $\mathrm{MoH}$, together with Caritas. Closer co-operation and permanent partnership with the $\mathrm{MoH}$, as one peer reviewer observed, raises its expectations. Another NSs, owing to a recent past tainted by unsavoury regimes, is still a bit reluctant to show closeness to the

\footnotetext{
${ }^{11}$ One PNS gave as the main reasons for working bilaterally: 1. 'tradition', 2. increased accountability to backdonors, 3. preference of its main back donor

12 The Phenomenon is not limited to the African continent, but recognized there by the Federation: "unless there is commitment and action by African NSs to transform [institutional infrastructure, management, accountability, partnerships, integrity etc.], outside assistance provided by partners will not make a major difference to the health and well-being of vulnerable people in Africa" [19]
} 
government. According to the issue, NSs work closely together with other Ministries and institutions: the Kazakhstan RC with the National TB Institute or the Norwegian RC with the Ministry of Justice for visiting prisoners.

Co-operation with universities is not as widespread yet, although many examples were found: In Togo, universities are involved in impact studies, in Kazakhstan, psychology students run a telephone hotline, and the Norwegian RC uses academic institutes for evaluations and needs assessments. It also uses university staff to lecture in seminars and managed on the other hand, to include 'RC topics' into academic curricula, e.g. refugee issues.

\section{Conclusions}

Numerous and varied were multilateral and bilateral partnerships observed and reported at country level. An easily neglected partner is the ICRC, which can give significant support to a NS, when present.

Sharing of findings and operational know-how was observed in a number of cases, even adoption of RC know-how by the MoH. Very common or probably the rule is membership by the NS in health-related national or regional committees.

Although anecdotal evidence points at an increase of non-Movement partnerships, in the meantime, the 30 or so PNSs working with poorer NSs are "like oxygen for the blood" for many of these. A clear trend over time to improvement of relationships between PNSs and NSs was found, as a result of a mutual learning process.

Preferences between bilateral and multilateral work among PNSs vary widely, so do criteria used by PNS for choosing partner countries. With regard to the field of work, PNSs tend to export their own know-how. No recipe has been found how to handle 'basket cases' of NS, the ones that have an integrity problem, for example; the Federation is thought to have to play the most important role.

The expression of the subsidiary role to the government varies between countries; but close co-operation with the $\mathrm{MoH}$ appears to the rule (and may raise its expectations).

\section{Recommendations}

The Federation should increase its efforts to support NSs in developing effective partnerships.

The bottom line for PNS programmes and project must be that they fit into the strategic plan of the NS, which must have the last say. PNSs should reinforce the trend away from being actors towards the development of the NS through mid- to long-term partnerships for programmes that include OD components.

The administrative overload of responding to different PNS requirements is to be alleviated by introducing common administrative procedures for one NS.

NSs should increase efforts to co-operate with universities: for evaluations and needs assessments, including students in RC activities or for university staff to lecture in seminars.

\section{Lessons learnt}

Short-term projects, though not necessarily, are liable to do more harm than good. 


\subsubsection{Partnership at operational level}

Closer to the ground, NSs work with an even wider range of government and civil society organisations. Co-operation with NGOs is common, especially with regard to HIV/AIDS (in Moçambique, Singapore, Uganda and Namibia). The Singapore RC conducts also international activities with NGO partners. Among the UN organisations, UNICEF was mentioned for Moçambique and PAHO in Honduras, were it financed during the first year a community mobilisation project for child health [22]. Co-operation is sometimes trilateral, e.g. with the MoH and an NGO (like in Kazakhstan with 'Project Hope'), or extends to whole networks, like in Honduras, including all major local stakeholders: schools, church, community leaders and the local $\mathrm{MoH}$.

Partnerships with the private sector were less frequently observed, but also reported. The Namibia RC, in fact, took some flak for working with a private health provider and not the $\mathrm{MoH}$ with anti-retroviral therapy. The Finnish RC works with the private sector for CBFA and many NSs commonly receive in kind donations from the private sector for disaster response.

The MoH appears again as important operational partner. In Honduras, volunteer activities are linked to the $\mathrm{MoH}$ health centres (including supply of consumables); in Namibia the $\mathrm{MoH}$ provides the biggest part of volunteer training, as well as educational material and condoms, and the Sierra Leone RC receives chlorine supply from the $\mathrm{MoH}$ for cholera prevention. Other state institutions appear as partners: in Norway, local authorities and the police for the 'Stop Violence' campaign, and local schools for the 'Respect RC Principles' campaign. And the ICRC appears once again, supplying the Armenian RC with lists of released prisoners.

Last, but not least: the community itself (see also in chapter 4.1.3.1. on Community involvement): ARCHI lists as one of the criteria for focus and decision-making: "Is the intervention supported by the community?" [18]. In Honduras, the community contributed the labour for the WatSan project, in Norway, nearly a whole town contributes to the annual fundraising fair and in Namibia, village committees select the RC volunteers.

\section{Conclusion}

Closer to the ground, NSs work with an even wider range of government and civil society organisations: NGOs, UN organisations, the local $\mathrm{MoH}$ or whole networks of local stakeholders, including schools, church and community leaders. Partnerships with the private sector were less frequently observed, but also reported.

\subsection{Health \& Care issues}

\subsubsection{HIV/AIDS: National Society presence in country response}

Activities of the Federation and the NSs in HIV/AIDS have increased incrementally since the Federation developed a global policy on HIV AIDS in 1987. At its General Assembly in 2001, the Federation took a truly global approach to the fight against HIV/AIDS, calling for its policy to be updated [23]. The role of the Federation was recognised in Article 34 of the declaration of the UN General Assembly Special Session on HIV/AIDS (UNGASS) 2001 [24]. Regional initiatives followed, especially in Africa, but also in other regions, such as in Latin America and the Caribbean, where the region defined as an indicator that "all NSs have incorporated the issue of HIV/AIDS in their permanent health programmes" [21]. The 
Federation also published a plethora of manuals and guidelines, for example on training, working with Orphans and Harm Reduction [6, 25, and 26].

In general, it has been observed that in rich countries, NSs have a smaller role in HIV/AIDS response owing to the strong presence of others (though even in poor countries, mushrooming of small NGOs was reported to tap into HIV funds). In those countries, NSs lend their name to advocacy; participate in World AIDS Day and in national network organisations and carry out prevention activities. In poor countries, while the disease is still on the increase, the $\mathrm{MoH}$ response capacity is often decreasing, as part of the 'triple burden'. Prevention is an activity common to all NSs, and often their main direction. Peer education from e.g. youth to youth is a common activity, such as the 'Expo-Sida' (in co-operation with Caritas) carried to schools by adolescents in Honduras. Many NSs produce publications for the general public, also for children, like the Namibia RC. Other NSs work with identified risk groups: the Kazakhstan $\mathrm{RC}$ with truck drivers, commercial sex workers and others, the Honduran RC with prisoners.

The fight against stigma and discrimination is relatively new for some NSs (like the Philippine RC). Others have been active for a while, such as the Honduran RC production (with Federation support) of the video film 'Breaking the Silence' [22]. Some NSs offer Voluntary Counselling and Testing (VCT): the Honduran RC for street children and blood donors [22], the Namibia RC for the general public ${ }^{13}$. Another important HIV/AIDS-related activity is work with Orphans and other Vulnerable Children (OVCs); Namibia, for instance, has a big and growing OVC problem and the NS can tackle only a small part of it. Linked to work with OVCs and generally, PLWHA, is the problem of Food Security, which by many donors appears not to be seen as an investment in health and livelihood.

Medical treatment of People Living With HIV/AIDS (PLWHA) can safely be left to the MoH in rich countries. For other countries, Federation guidelines stipulate that anti-retroviral therapy can be administered only when it is part of a comprehensive intervention, and that the $\mathrm{RC}$ will become involved only in collaboration with the government and/or other partners [27] - a policy which appeared to be respected in the review sample. In Namibia, for instance, anti-retroviral therapy is being introduced and available, although yet in widely insufficient quantities. The Namibia RC acts as an intermediary between institutions providing the therapy and the community, identifying and accompanying eligible patients. In the meantime, the Namibia RC runs a large volunteer program for home-based care (also for other clients). It is foreseen that with the increase of anti-retroviral therapy, the role of volunteers will gradually change from care of terminally ill patients to anti-retroviral therapy support. The Kazakhstan RC also checks compliance with anti-retroviral therapy of its clients in the Harm Reduction programme.

Intravenous drug users have also been defined as a vulnerable group requiring RC support [6]. Harm Reduction (consisting mainly in distribution of needles and syringes) acknowledges drug use without condoning it [ibid.]. The Italian $\mathrm{RC}$ has pioneered this programme, which has been adapted by many NSs, especially in the Eurasian continent, e.g. the one visited by the Kazakhstan RC.

How much progress has the RC made to empower PLWHA in the fight against HIV/AIDS, as advocated by the Federation [24]? Official partnerships with PLWHA associations have been concluded by many NSs: Namibia, the Philippines, El Salvador, Italy and others. The Latin

\footnotetext{
${ }^{13}$ the VCT centres 'New Start' are run like franchising by various civil society organisations, among them the $\mathrm{RC}$
} 
American and Caribbean RC network defined as an indicator that "all NSs have included associations of PLWHA in their activities and projects by..." [21]. The Federation reports that by May 2003, several NSs in the East Africa region had started partnerships with PLWHA associations, in Southern Africa [16]. In Namibia, RC and PLWHA association members are mutually board members of the other organisation and in Norway, a RC member is a board member of the PLWHA umbrella association. Both these NSs also provide office space (subsidised or not) to PLWHA associations. Other NSs, like the Nigerian, Honduran and Kazakhstan RC, still lag behind in forming official partnerships. But even some of those report working with PLWHA on individual basis for peer education, as recommended [28]. Other examples of operational co-operation are PLWHA working the therapeutic community run by the Italian RC, and clients participating in some of the home-based care volunteer meetings in Namibia. In a number of countries, PLWHA were reported to be volunteers themselves.

To be fair, in some countries PLWHA are still 'invisible' owing to the very high stigma; in Kazakhstan, there is only one PLWHA association in one major city; in Armenia, none at all. Where PLWHA are visible and organised, the NS itself can take the opportunity to manifest its solidarity: The Argentinean RC signed recently a co-operation agreement with a PLWHA association in the presence of the Minister of Health.

The number and kind of partnerships formed by NSs in the fight against HIV/AIDS is impressive. Within the Movement, the Norwegian RC, for instance, is member of the RC subregional network for HIV/AIDS; such (sub-) regional networks exist also elsewhere, like the Caribbean RC Network for AIDS. The Honduran RC has partnerships with NGOs, the MoH, and the GFATM; many NSs (Namibia and Nigeria RC, among others) form part of national and district AIDS coordination committees, and the Kazakhstan RC works closely with the national AIDS Centre. PNS-dependency, however, appears widespread; many NSs are limited in their range of action by limited funds: the Honduran RC works only with three out of five capable branches (through PNSs), and the Namibia RC can only tackle a small part of the work to be done with OVCs.

Another potential limiting factor, recognised by the Federation [16] are organisational fears that need to be managed. For the Honduran RC, working with men who have sex with men still seems a bit of a taboo (its neighbour NS in Guatemala was reported to be more progressive in this respect), so is work with commercial sex workers. Neither the Honduran nor the El Salvador RC - though they promote use - would distribute condoms as recommended by the Federation [4]. There are remainders of stigma within the NSs themselves: Kazakhstan RC volunteer groups were reported not imagining having PLWHA among family or friends.

Lastly, it must be acknowledged that HIV/AIDS is much broader than a health issue. The profile and funding for AIDS has created many opportunities for expansion of a range of Health programming, and programming beyond Health, e.g. Youth and Humanitarian Values.

\section{Conclusions}

Significant presence of the Federation and the NSs in HIV/AIDS the global response came late. Since, incorporating HIV/AIDS in permanent health programmes has become near universal, though in rich countries, NSs play a smaller role owing to the strong presence of others. Lending the RC name to advocacy and prevention (for the general public and target groups) are most common activities. Fight against stigma and discrimination is still relatively 
new for some NSs. Other activities observed are Voluntary Counselling and Testing, working with Orphans and other Vulnerable Children, home-based care for AIDS patients, linking patients up with anti-retroviral therapy, and Harm Reduction.

Progress made by NSs in empowering PLWHA in the fight against HIV/AIDS varies between close mutual co-operation and visible institutional solidarity and timid individual co-operation only, if at all. On the other hand, the number and kind of general partnerships formed by NSs in the fight against HIV/AIDS is impressive.

The main limiting factor for the scope of work is limited funding; some NSs implement only programmes supported by PNSs. Another potential limiting factor is organisational fears and residual stigma within the RC.

\section{Recommendations}

The Federation must continue its efforts to encourage and support all NSs to play a significant role in HIV/ AIDS response, through internal advocacy, capacity building and facilitating access to funds (e.g. the GFATM). Care must be taken that no aspects relevant for a given country are neglected.

Where PLWHA are 'invisible', this should trigger an increased effort to fight against stigma and discrimination. A NS may also play an important role in helping PLWHA to get organised.

\section{Lessons learnt}

As an integral part of civil society, the $\mathrm{RC}$ itself is not immune to stigma and discrimination.

\subsubsection{National Society presence in response to other health priorities:}

Evidence found is sketchy, but points at a considerable range of national health priorities NSs engage according to local needs ${ }^{14}$ :

- The Nigeria RC is a member of a national working group for immunization;

- The Singapore RC has been engaged in SARS prevention and psychological support;

- The Moçambican RC is engaged in combating seasonal cholera outbreaks and in distributing impregnated mosquito nets;

- The Sierra Leone works with nutrition and Food Security and helps combating seasonal cholera outbreaks;

- The Honduran RC works with IMCI in 190 communities;

- The Kazakhstan RC runs six TB projects, including food parcels;

- The Namibia RC participates in community mobilisation for the national immunisation day;

- The Philippine RC participates in campaigns for elimination of malaria, measles and dengue;

- The Norwegian RC targets lonely people and others who are socially vulnerable;

- The Ugandan RC participates in community mobilisation against malaria and for EPI.

\footnotetext{
${ }^{14}$ Part of these and others, not considered here, form part of emergency response rather than standing programmes; H\&C activities as part of emergency response can be important both in relation to impact and budget, but were not part of this review
} 
NSs are often aware that their means and capacity are limited to tackle other relevant national health problems; the Namibia RC would like to engage in the fight against TB and malaria, for example ${ }^{15}$. Other emerging needs are traffic accidents, perceived by the Latin American and Caribbean Region.

\section{Conclusion}

NSs engage in a wide range of health priorities according to national needs; some, however, are severely limited in doing so by their funding situation.

\section{Recommendation}

The Federation and NSs should take care not to neglect national health priorities other than HIV/AIDS - without, however, spreading resources too thinly.

\subsubsection{NS presence in 'traditional' activities}

Blood banks and blood donor recruitment, ambulance services, provision of curative care, Nurse training and First Aid are the most common 'traditional' RC activities. There is no scope within this review to unravel their history, but an important clue was given by the VicePresident of the Federation: "the Italian RC has supported the State when Italy was poor" which is not so long ago, after all.

A number of NSs were never or hardly burdened with traditional activities: the Danish, Armenian RC and the Kazakhstan RC, for example. Others - many - have handed over to the $\mathrm{MoH}$ all or some of them before the end of the $20^{\text {th }}$ Century:

- The Singapore, Italian, Swedish Norwegian and Fiji RC: blood banks,

- The Norwegian, Ugandan, Fiji and Italian RC: hospitals and/or nursing schools,

- The Norwegian RC is reducing the professional ambulance service, which is gradually taken over by the $\mathrm{MoH}$,

- The Swiss RC is about to disengage from its nurse training schools.

Some of these activities are income-generating: curative health services, provision of First Aid during public events or First Aid training, and ambulance services. The Argentinean and Finnish RC therefore treat their health care institutions and nursing schools as "pure business"; the Finnish RC has transformed them into a completely separate entity. The professional ambulances service of the Norwegian RC remains functionally (though not structurally) somewhat intertwined with the $\mathrm{MoH}$ ambulance service ${ }^{16}$.

The RC is proud to have remained the world's leader in First Aid [2]. First Aid occupies a privileged place among the traditional activities owing to its multiple functions: arguably, it serves people who are momentarily vulnerable; it can also be income generating, guarantees high visibility and can serve as an entry point for volunteer recruitment. Ambulance services represent another face of pre-hospital care. Most, like in Italy (the Italian RC runs 3'586 ambulances) and Honduras, are paid for by the $\mathrm{MoH}$. The Singapore RC, on the other hand, keeps only a subsidised ambulance service for non-emergency transfers for the poor. First Aid too can be updated for modern social and health issues, particularly through first ad drug and

\footnotetext{
${ }^{15}$ In Namibia, malaria is the leading cause of death and illness among children under five; Namibia is also the third worst TB-affected country in the world [29]

${ }^{16}$ Through human resources: RC ambulance drivers aspire to become MoH employees
} 
alcohol emergencies. Such work is a good entry point for harm reduction work, relevant to rich and poor NSs alike

A number of NSs are involved in provision of curative care and nurse training: the French, Spanish, Japanese, Colombian, Paraguayan and Venezuelan RC run hospitals and/or health centres; in the Americas, $15 \%$ of NSs are involved in nurse training [20]. The Sierra Leone $\mathrm{RC}$ runs $\mathrm{MCH}$ clinics, which it uses as reference point for volunteers; the Moçambican RC runs 'First Aid Posts' - which de facto provide PHC services - that it would willingly hand over to the $\mathrm{MoH}$ if possible.

The picture for blood banks is ambiguous. As mentioned above, many NSs have handed them over; the Federation closed its blood transfusion unit in the Secretariat around 1996. Still, the $\mathrm{RC}$ is involved in the collection of approximately two-thirds of the world's blood [30]. Some NSs contribute to about half of their country's blood supply (Honduras, Colombia); others (Finland) are reported to have the monopoly. The Federation itself argues that this activity is "...based upon the charitable health service model", and that "the imperatives and expectations of the community today indicate a need to convert such a model to that more appropriate for a manufacturing/ pharmaceutical facility. It is acknowledged that such a change in thinking or culture may be very difficult" [31].

The RC is proud to have retained international leadership in the promotion of voluntary, nonremunerated blood donation [2] and promotes it, for example, in a memorandum published together with WHO [14]. No ambiguity here: this activity remains community based and complementary to the $\mathrm{MoH}$. The Norwegian $\mathrm{RC}$, for instance, which has handed over its blood banks, has actually reinforced its donor recruitment status and increased international activities. In the Americas, $70 \%$ of NSs inform that they promote voluntary, non-remunerated blood donation [20].

\section{Conclusions}

A number of 'traditional' activities are completely outdated in the sense that they do not serve the most vulnerable. Many NSs have handed over to the $\mathrm{MoH}$ all or some of them before the end of the $20^{\text {th }}$ Century. Unease exists e.g. about curative care activities; some NSs treat them as separate, purely income-generating entities.

First Aid occupies a privileged place among the traditional activities owing to its multiple functions. While there is disparity between the discouraging discourse of the Federation towards RC involvement in blood banks and the globally high portion of blood products manufactured by NSs, the attitude of the Federation and NSs towards promotion of voluntary, non-remunerated blood donation is unambiguously supportive.

\section{Recommendations}

To conduct an in-depth evaluation of 'traditional' activities, with specific focus on the ones with which many NSs are not quite at ease: curative health care and nursing schools, professional ambulance services and blood banks.

\subsubsection{Water and Sanitation}

The Federation plans to increase its engagement in this field, hoping that the launching of a $2^{\text {nd }}$ UN Decade for Water in 2005 will make more funds available for WatSan projects worldwide [32]. The Federation also plans to increase the share of developmental project 
(currently just below 30\%) as opposed to disaster relief projects [33]. Larger, longer-term projects should allow for economy of scale and more secure resource mobilisation [32]. The Federation is ready to assist NSs with preparing proposals and presenting them to potential donors and partners [34].

Other strategic changes concern impact and sustainability. The Federation and NSs have realised that the hardware aspects of WatSan interventions are easier to implement compared to the software aspects [35] such as: community participation, community fundraising and maintenance training, and behavioural change in hygiene practices [33]. Sustainability considerations have also attracted increased attention [36]: in the Southern Africa Region, for example, it was observed that project were 'better' with direct Federation support, but collapsed when the Federation delegates left [37].

The review visited only one WatSan project, in Honduras. Others were reported by NSs in Namibia, the Philippines, Sierra Leone, El Salvador and Moçambique. Anecdotal evidence was found that the some of the above mentioned strategic changes are being implemented. The Philippine RC integrates WatSan activities in community-based PHC; in El Salvador, the NS insisted in community participation and health promotion with a PNS that just wanted to build latrines; the Namibia RC introduced a strong health promotion component (including distribution of ORS) in its WatSan project after an evaluation revealed it to be lopsided towards hardware. From the PNS side, the Norwegian RC reports always to insist on important development component in WatSan activities.

\section{Conclusion}

The Federation plans to increase its engagement in the field of Water and Sanitation. It is ready to assist NSs with preparing and presenting proposals, and plans to increase the share of developmental projects in relation to disaster relief. 'Software' aspects are to gain importance in relation to hardware; sustainability is to be stressed. Anecdotal evidence was found that the latter considerations are already being made.

\subsection{Ethical issues}

Among interesting and relevant crosscutting issues (gender and environment being more usual suspects), this review has tried to give special attention to matters of ethics. Without dealing with any of them in depth, some of them are flagged up here, with the intention to stimulate thoughts and possibly, discussion.

- Financial accountability: a rare case of diversion of funds at branch level was dealt with from HQ with the severity it would be in the private industry.

- Accreditation and certification: in one country, volunteers involved in first aid and ambulance service were not accredited by e.g. the MoH. In another country, the Federation delegate, a medical doctor, was not allowed to participate in hospital ward rounds (which is the best way to gauge the capacity of second-line a health service).

- How much can the RC offer? Volunteers keep registering orphans and vulnerable children (among them child-headed families, or one grandmother in charge of seven children). With no OVC project in the province, nothing can be done for them. Or volunteers doing home visits to AIDS patients are afraid to ask them: "have you eaten?" - in many instances, they haven't and the RC has no food parcels to offer. 
- Raising hopes - and dashing them: one NS had just won the trust of 38 intravenous drug users, when funding, and the programme, was discontinued.

- Stigmatised by the RC? Some potential clients refuse home-based care visits for fear of stigma (home visits by strangers do raise neighbours' curiosity). So some volunteers avoid using RC insignia for visits to private homes. Also, gathering children of vulnerable parents in one group identifies - and stigmatises - them as such.

- Confidentiality 1: one NS has signed an agreement with the Ministry of Interior prior to starting its Harm Reduction programme, to be sure that the identity of its clients is not revealed. Instead of names, codes are used for monitoring.

- Confidentiality 2: what if the home visiting volunteer notices that the son of the old lady client steals her money to fund a drug dependency habit?

- Confidentiality 3: the local municipality does not give information to the RC as to who is lonely (and may benefit from home visits); social workers, however, leave a RC flyer at such peoples' homes, possibly accompanied by more active propaganda.

- Allocative efficiency: within a (sub-) region, does the Federation allocate funds among the NSs 'equally', or according to size, needs, relative living cost or NS capacity?

- The 'use' of affected people: from 'client-tourism' (e.g. the use of photographs for documenting or fundraising) to 'assessment fatigue' caused by visits without ensuing assistance.

- Another volunteer, please!? An old lady in Europe refuses home visits by volunteer of African origin (the NS did not send another one).

- 'Clean' volunteers, please! A European NS is pushing for legislation to guarantee that volunteers working with children have a clean police record.

- Human resources Realpolitik: a NS decides to hire a fundraiser who belongs to the same ethnic group as the ruling class - whose language the candidate must speak, after all. It cannot, of course, advertise explicitly for such a person. Nor can a NS advertise explicitly for volunteers that speak the language most commonly spoken by prisoners, who tend to be of roughly the same foreign origin.

- Role misperception: it may not be obvious for a prisoner that a visiting $\mathrm{RC}$ volunteer is neither a potential lover nor a psychologist, but just a link to the outside world. (The NS has a rule that the volunteer will be changed upon release.) Other strict rules and regulations apply for volunteers visiting prisoners, e.g. not to take or bring letters.

- Extreme impartiality? The candidate who excludes visiting a child abuser in prison cannot become prison visiting volunteer.

- Making promises for others: the home-base care volunteer refers a client to the $\mathrm{MoH}$ service, which is not able to provide the required service.

- A difficult choice between two goods: volunteers must choose among HIV/AIDS patients eligible for anti-retroviral therapy... 
- A moral dilemma? Can TB patients initially hospitalised be put under treatment if the $\mathrm{RC}$ volunteers in their home province have not had DOTS training? (They can't).

- How much is a gift? Can a home visiting volunteer accept regular, big gifts? Money?

- The NS as part of Society: condom distribution is not practice everywhere yet. On the other hand, one NS is not allowed to distribute them neither in high schools nor in prisons, despite demand.

- Attention to detail: the moral obligation not to overlook any vulnerable group leads to making RC buildings accessible for the handicapped.

- Too close for comfort? A European NS is discussing whether its accentuated subsidiary role to the state is not compromising impartiality. Another NS keeps the state at a certain distance because it is still tainted by years of an unsavoury regime.

\section{Conclusion}

A branch manager mentioned the constant danger that the $\mathrm{RC}$ would "change from an idea into a firm". In these ethical issues, the power of humanity, or rather its limits, sometimes becomes more visible again. 
Annex A
Strategy 2010 - Thematic Review

Health and Care in the Community

\section{Background}

The International Federation has a long tradition of working in the area of health and care. Since the adaptation of Strategy 2010, major health related strategies and policy documents on HIV/AIDS and other infectious diseases have been formulated to be implemented by NSs in different regions. In addition, a number of health and care reviews/evaluations have been carried out.

The auxiliary role of Red Cross and Red Crescent National Societies to their national governments in the area of health is achieved through an extensive network of volunteers working in the communities. The Red Cross and Red Crescent volunteers complement the governments' health service efforts through social mobilisation, health education, first aid, psychological support and community care. The focus of these interventions is to give people the knowledge and tools they need to facilitate processes that alleviate and reduce vulnerability.

During the last four years the Federation health programmes in different regions have contributed in:

a) increasing the awareness of the community on HIV/AIDS and on prevention methods through information campaign and structured health education activities based on peer education approach

b) supporting PLWHA and family members through home based care and support programmes

c) increasing the awareness of the society for the reduction of stigma and discrimination through conducting global antistigma campaigns that cascaded down to the community

d) supporting governments in significantly increasing the polio and measles vaccination coverage through effective community mobilization

e) educating the community and increasing the distribution of bed nets for the prevention of malaria

f) the control of major epidemics that have occurred in disaster settings and in the general population

g) providing potable water and in improving the environmental sanitation for over 5 million people living in difficult situation including disaster settings

h) increasing the awareness of the community for the promotion of hygiene and improvement of environmental sanitation

\section{The Review}

When adopting Strategy 2010 in 1999, the General Assembly requested the Governing Board to "initiate the process of reviewing and updating the strategy during the decade for consideration by the General Assembly". Mid-term evaluation is provided for within the implementation framework of the Strategy to assess the progress of the various components of the International Federation against the strategic directions and to examine if the activities and programmes remain in line with the agreed priorities of the Strategy 2010. The evaluation is to help identify the most effective and efficient ways for managing and fostering the four core areas and strategic directions of Strategy 2010. The findings from the evaluation are also expected to generate lessons for improving the implementation the Strategy at various levels - 
local, national and global. The exercise will determine what aspects of the Strategy are ontrack, and whether adjustment or corrective action is required, and to enable timely reorientation and re-alignment of the Strategy 2010.

The thematic review of the area of health and care in the community forms a part of the midterm review of Strategy 2010. The review will assess progress of in the area of health and care in community against the three strategic directions of the Strategy 2010 at local, regional and global level.

\section{Objective}

The aim of this review is to learn from implementation experience and feed into the Strategy 2010 review and to encourage discussion in the Federation in relations to:

a) extent to which health program are in line with Strategy 2010;

b) lessons to be learned from actions at the community leveling terms of community engagement and responsiveness of programs in addressing the felt needs of the community

c) assess the contribution of the Red Cross and Red Crescent health programmes to the Millennium Development Goals; and

d) study how vulnerability and its consequences on health are defined and understood at various levels of the Federation.

e) assess the established working relationship with Ministry of Health and its impacts in facilitating implementation of programs.

\section{Key Issues to Covered}

Within the above objectives and established evaluation criteria, the following issues will be examined by the review:

B Assess the progress of the application of Strategy 2010 as related to health and care programmes.

B Identify the factors which facilitated or hindered implementation processes of the health and care programmes as outlined in Strategy 2010.

B Analyse whether National Societies have been focused and responsive in their national and local health programmes.

B Explore the perception with regard to progress made in building National Society capacities to design and effectively implement health problems identified by the communities.

B Examine if adequate partnership have been fostered to enhance outcomes and financing.

B Study how Strategy 2010 objectives are integrated to the health policies and strategies at Federation, national and local level.

B Examine if National Society governance and management provided the required support and direction in the health related efforts.

B Assess the quality of planning and programme development.

B Study the mechanisms adopted by National Societies to actively involve volunteers.

B Examine if systematic monitoring and evaluation mechanisms have been put in place at all levels.

B Assess the value addition of Red Cross and Red Crescent to the countries health.

B Explore the adequacy of the baseline information.

B Assess the contribution of health related efforts to the Millennium Development Goals. 


\section{Intended use}

The primary client for this review is the General Assembly and the Governing Board to update the Strategy 2010. The Federation health programme will benefit through an active dialogue on lessons learnt . The review also has the potential to be circulated more widely and hence may provide a learning opportunity for the humanitarian community in general and be part of our policy dialogue with the external stakeholders.

\section{Methodology}

B A review of all relevant documentation and evaluations carried out in the past; the key documents are:

a. Reducing household vulnerability to HIV \& AIDS and other infectious diseases

b. Equity and Health in the Americas

c. African Red Cross Red Crescent Health Initiative 2010

d. Annual country plans on health

e. Seven country case study evaluating the International Federations response to the challenge of the HIV/AIDS pandemic

f. Health global appeals and programme updates

g. Health policies on each of the 5 countries to be reviewed

B Interviews with National Society representatives, donors, health related personnel at government level, the health commission and the Stockholm group, as well as partners at country, regional and global level

B Field visits to the five selected countries, one from each region ${ }^{17}$

The exercise is expected to take five weeks. Start date will be in the first week of November 2004. An approximate time allocation is four days for literature review, two days for meeting staff at the Secretariat, four days for telephone interview with Regional Delegation and National Societies ICRC and external agencies, ten days for field trips and four days to prepare and present the report.

\section{Review team}

The review team should consist of one external consultant-team leader, with an expertise in Public Health; one resource person from the Secretariat health department; and one participant from the National Society with background in health.

\section{The External Consultant}

The successful Consultants is likely to possess:

- Higher education and experience in Public Health policy.

- Knowledge of the systems of RC/RC Movement.

- Capacity to analyze and articulate lessons learnt in the context of complex network of organizations.

- Experience in evaluation and preparing analytical reports.

- Good interview and interpersonal skills

- Proficiency in English language

\section{Outputs}

The expected outputs are:

\footnotetext{
${ }^{17}$ Countries are to be selected on the basis of volume of health programs being implemented for at least two years and over, consistency in program implementation (no interruption) especially in areas of HIV/AIDS, measles and polio vaccination and malaria
} 
B inception report, up to 3 pages with a chapter plan and key areas of enquiry to be submitted within four days of start of the consultancy.

B draft report, within one week of completion of field work

B final report, due $\mathbf{1 5}^{\text {th }}$ January $\mathbf{2 0 0 5}$, consisting of key findings, conclusion and recommendations. In addition, it will have the following:

a) results framework to measure progress

b) stand alone-executive summary of less than five pages.

\section{Management of the Review}

The review will be managed by the Evaluation Department in close collaboration with the Health Department.

\section{Deadline: $27^{\text {th }}$ October 2004}




\section{Annex B Strategy 2010 Health \& Care review - inception report}

\section{Introduction}

This thematic review of the area of health and care in the community forms a part of the midterm review of Strategy 2010. Its aim is to learn from implementation experience and feed into the Strategy 2010 review and to encourage discussion in the Federation in relations to:

f) extent to which health program are in line with Strategy 2010;

g) lessons to be learned from actions at the community leveling terms of community engagement and responsiveness of programs in addressing the felt needs of the community

h) assess the contribution of the Red Cross and Red Crescent health programmes to the Millennium Development Goals; and

i) study how vulnerability and its consequences on health are defined and understood at various levels of the Federation.

j) assess the established working relationship with Ministry of Health and its impacts in facilitating implementation of programs.

The investigation is an iterative process; this inception report represents a starting point only and not the final study design. It is hoped that the review will also have some value for National Societies that were not part of the study, with regard to self-assessment about the direction taken in $\mathrm{H} \& \mathrm{C}$, evaluating progress and the potential for strategy changes.

\section{Method, expected output}

Methods employed are document review, literature study, telephone interviews (preceded by the distribution of the interview guide via electronic mail), and face-to-face interviews, according to availability: with National Society representatives, donors, health-related personnel at government level, the health commission, the Stockholm group and partners at country, regional and global level). Field visits to three to four selected countries ${ }^{18}$ will be carried out, together with a peer reviewer from a National Society. The expected output - by mid-January - is a report with the usual components: introduction, methodology, findings, conclusions, recommendations and lessons learnt, and an executive summary.

\section{Issues to investigate}

The review according to the ToR attempts to cover a very wide range of issues; to investigate them depth is beyond the scope of a five-week study. The reviewer will cover the range as widely and in-depth as possible, but focus primarily on a number of key issues, listed in italics. The grouping of issues follows largely the structure proposed in the approach paper for the 2010 mid-term review.

\subsection{Responsive and focused}

a) global/regional

- Management and visibility of the collective contribution to health-related Millennium Development Goals

- Demonstration of collective progress towards Strategy 2010 in terms of client outcomes

- Additions needed to make 2010 more operational

\footnotetext{
${ }^{18}$ Honduras, Kasachstan, Indonesia
} 
- Resilience and flexibility of the Federation to manage in the current global environment

b) country level

- Are the health programmes in line with 2010? Progress made?

- Shift from disaster victims to 'structural vulnerability'

- Definition of vulnerability and its consequences on health

- $R C / R C$ contribution to national health priorities

- Relevance of RC/RC activities for affected population, beneficiaries, NS, IFRC, MoH

- What is not done (e.g. working in the slums)?

- Importance of understanding of public health (e.g. determinants of ill-health) in order to allow for more holistic approach

- Use of NS policy dialogue to influence public sector policy and programs in core areas

- Engagement of all other stakeholders (including beneficiaries, Government, PNS's, IFRC, other humanitarian agencies, UN/EU etc.) for $\mathrm{H} \& \mathrm{C}$ programme planning

- Use of a structured planning process (incl. monitoring and evaluation)

- The making of operational choices by a NS (influence of Movement, MoH, donors...)

- Link between Health and Care/Social Welfare

- Link of service delivery and advocacy

- Is there sharing with other parts of Movement (Federation, Region, NS) and externals

- Support received/desired from the Federation/ Secretariat

c) operational level

- Are programmes focused and impact-oriented?

- Factors that facilitated or hindered implementation processes of $\mathrm{H} \& \mathrm{C}$ programmes

- Correspondence with felt needs at community level

- Use of baseline data, outcome and impact measurement (attribution?)

- Use of standards

- Community/beneficiary satisfaction

\subsection{Well functioning National Society}

a) global/regional

- The Federation as trusted, independent global institution - partner of choice

- Added value of Federation/Secretariat for NSs: does it have a policy and tools to achieve unity of purpose and action?

- Use of Federation-wide results-based evaluation system to scale up IFRC impact and build capacity

b) country level

- Awareness of strategy 2010 Has is made a difference?

- Difference of 'RCness'; comparative advantage? Change over time? Missed opportunities?

- Provision of required support and direction in $H \& C$-related efforts by NS governance and management

- H \& C Structure at HQ and Branch level, structural stability

- NS resource mobilisation and financial solvency for H\&C programmes

- Definition of 'functioning' branches 
- Presence of technical core staff, availability of funds to invest in them

- Enhancing RC/RC image and self image in health? (e.g. publications, participation in conferences...)

- Accountability: relative to 2010, to the Federation, beneficiaries, donors and other stakeholders

- Trust by donors in the NS

- Added value of technical regional resource persons and regional networks

c) operational level

- Identification of the vulnerable

- Volunteer satisfaction with their work

- Building of local capacity

\section{3..3 Working together effectively}

a) global/regional

- Co-operation of Secretariat and National Societies to ensure that multilateral actions operate effectively

- Value of partnerships for building consensus and contributing to learning; partnerships as long term relationships or driven by shorter term project horizons.

- Working in a consortium can give access to new, local or regional, funds, decreases the dependency from isolated Federation appeals

b) country level

- Operating more effectively and strengthening the Movement and the NS through biand multi-lateral interventions

- Leadership by NS in non-official partnerships to leverage national resources for the vulnerable

- Sharing of assessments and operating functions; success of collaborating arrangements.

- Membership in national or regional committees

- Over-emphasis of partnerships within Movement?

- Relationship with PNSs

- Role of RC principles and humanitarian values to influence decisions in partner organisations

- Relations to $\mathrm{MoH}$ and links with academic institutions

- Controversial partnerships?

c) operational level

- Partnership at operational level with other NGOs, donors and private sector

- Community engagement

\section{$\underline{\text { 3.4. Sectoral and specific issues }}$}

\section{HIV/AIDS}

- NS presence in country response

- Empowerment of PLWHA in centre of triangle: prevention, stigma, treatment

$\mathrm{H} \& \mathrm{C}$ issues

- NS presence in response to other health priorities: $\mathrm{MCH}$, malaria, $\mathrm{TB}$, measles, polio 
- NS presence in 'traditional' activities: blood donation, first aid

- NS presence in health emergencies, mobilisation, community care, WatSan

WatSan

- Better balance between hardware and software?

Ethical issues

- substandard drugs

- licence to practice for foreigners

- others?

\subsection{Performance indicators}

The review will attempt to identify a small number of performance indicators that could be used by the Federation to measure progress within the framework of Strategy 2010. Examples:

- Practical examples of involvement of vulnerable people, e.g. PLWHA

- Has a photograph of the NS president with PLWHA been published in the newspaper?

- Existence in the NS of a department or person for volunteers (alternatively: does every staff member resource volunteers?)

- Membership of a volunteer representative on the board of the NS

- H \& C Programmes attract longer-term and more significant funding levels with lower costs per beneficiary

- Formal agreement exists between NS and the MoH defining roles and responsibilities of both for long-term part

Dr M. Michael, Geneva, 3 December 2004 


\section{Annex C: References}

1. IFRC (2004) Meeting in Copenhagen on $15^{\text {th }}$ October 2004, regarding health priorities in the Federation (summary)

2. IFRC (2004) Health and Care - Appeal 2004

3. McAllister E (2004) IFRCF Strategy 2010 Mid Term Review Approach Paper

4. IFRC (2000) THE INTERNATIONAL FEDERATION OF THE RED CROSS AND RED CRESCENT SOCIETIES AND THE MILLENIUM DEVELOPMENT GOALS. Protecting Human Dignity

5. Namibia RC Society (2004) Annual Report 2004

6. IFRC (2003) Spreading the light of science. Guidelines on harm reduction related to injecting drug use

7. IFRC (1999) Strategy 2010. To improve the lives of vulnerable people by mobilising the power of humanity

8. Norwegian Red Cross and econ (2001) Social Pulse 2001. Flaws in the welfare society.

9. Namibia Red Cross Society (2004) Namibia Red Cross Society Annual Report 2003

10. IFRC (2004) "Our Federation of the Future" Discussion Paper on External Trends

11. Norwegian RC (2002) Annual Report 2002

12. IFRC (2003) Southern Africa... Not business as usual

13. IFRC (2001) Ouagadougou Declaration

14. IFRC, WHO (2003) Memorandum of Understanding for Collaboration between the World Health Organization, South-East Asia Regional Office and the International Federation of Red Cross and Red Crescent Societies

15. IFRC (2004) Health and Care - Programme update \#1

16. UNAIDS, IFRC, GNP+ (2003) A vital partnership: the work of GNP+ and the

International Federation of Red Cross and Red Crescent Societies on HIV/AIDS

17. Healthy Family (2002) Healthy Family Project

18. IFRC (2000) ARCHI 2010, making a major difference to the health of vulnerable people in Africa

19. IFRC (2003) Implementation of Strategy 2010. The Africa perspective. Two years since the commitment at Ouagadougou: ARCHI 2010, HIV/AIDS, food security and volunteer management

20. IFRC (2003) Equidad y Salud en América.

21. IFRC (2002) plan de Acción América Latina y el Caribe. CORI : Comité Regional Interamericano

22. Cruz Roja Hondureña (2004) Memoria 2002-2004

23. IFRC (2002) Federation HIV/AIDS Policy

24. IFRC (2003) Community home-based care for people living with HIV/AIDS. A framework for National Society programming

25. IFRC (2000) action with youth. HIV and STD: A training manual for young people

26. IFRC (2002) Orphans and other children made vulnerable by HIV/AIDS. Principles and operational guidelines for programming

27. IFRC (2004) Service delivery model on access to care and antiretroviral therapy for people living with HIV/AIDS

28. Corcoran B, Hunt M (2003) A seven country case study evaluating the International

Federation's response to the challenges of the HIV/AIDS pandemic. Jamaica 12-16 May 2003

28. Government of the Republic of Namibia and UN (2004) United Nations Namibia

Common Country Assessment 2004. Advance copy

30. IFRC (2002) Reducing household vulnerability to HIV/AIDS and other infectious diseases 
31. IFRC (1998) Blood programme. Quality manual

32. IFRC (2003) Ensuring safe water and sanitation. Improving health and care in the community.

33. IFRC (2004) GWSI: Global Water and Sanitation Initiative. PowerPoint presentation

34. IFRC (2004) GWSI: Global Water and Sanitation Initiative. Information Sheet No 1

35. IFRC (2003) Policy, Water and Sanitation

36. IFRC (2004) Global Water and Sanitation Initiative (GWSI) Project Design Checklist ( $1^{\text {st }}$ draft, August 2004)

37. IFRC (2002) Establishing and 'Scaling-up' a Regional Programme. Lessons learned from the Regional Water \& Sanitation Programme (Southern Africa Region) 1997-2002

Other documents consulted:

IFRC (2003) Report of the Health and Community Services Commission. INTERNATIONAL FEDERATION OF RED CROSS AND RED CRESCENT SOCIETIES XIVth Session of the General Assembly

IFRF (200?) International Federation Vulnerability and Capacity Assessment Guide

Corcoran B, Hows JV, Wall B (2003) A seven country case study evaluating the International Federation's response to the challenges of the HIV/AIDS pandemic. Latvia 5-9 May 2003

McAllister E (2004) To improve the lives of vulnerable by mobilizing the power of humanity.

IFRC (2003) Strategy 2010: National Society Process. Analysis from Self-Assessment 20002003

IFRC (2004) Draft Health \& Care Generic Activity Indicators ( $2^{\text {nd }}$ version of 19/10/04):

IFRC (2003) Reducing household vulnerability to HIV/AIDS in selected countries of Asia and the Pacific. 2003 Report, OPEC fund

IFRC (2002) Volunteers and community health. ARCHI 2010. Sharing ideas and experiences

IFRC (2001) Improving health and care in the community. Red Cross \& Red Crescent action

Namibia Red Cross Society (2004) Red Cross News. The Namibia Red Cross Society's Newsletter 2004

Government of the Republic of Namibia and the United Nations System in Namibia (2004) United Nations in Namibia, common country assessment. Advance copy

Norwegian RC (2002) Strategy for the Norwegian Red Cross: The will to help - the strength to act.

Stein-Eric Kruse (2003) A Review of Global Programmes in the Red Cross Movement. A Report to NORAD. Centre for Health and Social Development

IFRC (2003) Strategic Direction 2+2. Almaty Regional Delegation March 2003 
Strategy 2010 - Health \& Care Review

American Red Cross (2003) Strategic Direction for Europe, Central Asia and Middle East Region 2003-2005. American Red Cross International Services 


\section{Annex D: Itinerary and contacts M. Michael and peer reviewers ${ }^{19}$}

Saturday 27.12. - Sunday 28.12. 2004

São Paulo - Zurich

Monday 29.11. 2004

Briefing by Amna Al-Ahmar, Mathew Varghese, Getachew Gizaw, Bruce Eshaya-Chauvin, Grace Lo Yuen Fong, Jean Roy

Tuesday 30.11. 2004

Briefing by Uli Jaspers, Bernard Gardiner, Lasha Goguadze

Literature study, work on inception report

Wednesday 1.12. 2004

Briefing by Hakan Sandbladh

Literature study, work on inception report

Thursday 2.12. 2004

Interview with Getachew Gizaw and Bruce Eshaya-Chauvin

Literature study, work in interview guide

Friday 3.12.

Disscussion of inception report with Amna Al-Ahmar, Mathew Varghese, Getachew Gizaw, Jean Roy and Dr Fidel

Saturday 4.12. - Sunday 5.12. 2004: off

Monday 6.12. - Tuesday 7.12. 2004: $\operatorname{standby}^{20}$

Saturday 8.11. - 12. 2004: off

Sunday 12.12. 2004

Travel Zurich-Miami

Monday 13.12.2004 travel Miami-Tegucigalpa ${ }^{21}$

Introduction to Nelson Aly, Federation delegate, Dr Salvador A. Molino, peer reviever Salvadoran Red Cross. Establishing agenda with Marcia Garcia, HRCS OD co-ordinator Interview with Dr Salvador A. Molina

Tuesday 14. 12.2004

Interview with Patricia McLaughlin, Program Advisor American Red Cross

Interview with Marcos Antonio Ramos, project manager 'Ciudad Espana'

Visit to 'Ciudad Espana', group interview with four women volunteers

Interview with Claudio Stauffer and Sonia Bueso, Swiss Red Cross

Interview with Dr Salvador A. Molina

\footnotetext{
${ }^{19}$ Details of the first trip, to Nigeria, see last page of this annex

${ }^{20}$ Owing to late cancellation of first leg of trip

${ }^{21}$ Delay of one day owing to harassment by US immigration
} 
Wednesday 15.12.2004

Interview with Dr Joel Durón, health co-ordinator HRCS

Interview with Cristian Zamora, Youth programme co-ordinator HRC

Interview with Dr Maria Isabel Gudez, MoH (MCH)

Visit to HRCS Youth programme in San Francisco, Group interview with HRCS coach Denis

Martínez and adolescent participants

Interview with Dr Salvador A. Molina

Peer reviewer Dr Salvador A. Molina:

Group interview with volunteers of Perspire branch

Interview with María Carmen Flores, $\mathrm{MoH}$ nurse in Perspire

Group interview with five voluntaries of villages of San Antonio de Padua, Perspire

Group interview villagers of La Laguna in San Antonio de Padua, Perspire

Thursday 16.12.2004

Visit to Sanitation Project in Colonia Vista Hermosa, group interview with community leaders, interviews with beneficiary.

Visit to Sanitation Project in Colonia Fátima, group interview with community leaders, six individual and group interviews with randomly chosen inhabitants

Interview with Francisto Orlando Vega, WatSan project manager HRCS

Interview with Ones García, HIV/AIDS programme co-ordinator HRCS

Interview with Arnaldo Alvarez, volunteer co-ordinator HRCS

Interview with Dr Salvador A. Molina

Peer reviewer Dr Salvador A. Molina:

Interviews with families in Colonia Vista Hermosa

Interview with Dr Luis Miguel Amendola, MoH co-ordinator PAHO

Interview with Marelly García, Coordinadora de la junta Directiva de ASONAPVSIDAH (association of PLWHA)

Interview with Dora Martínez Médico, Iglesia de Santidad Amor y Vida

Friday 17.12.2004

Interview with Marcia Garcia, HRC OD co-ordinator

Interview with Interview with Dr Joel Durón, HRCS health co-ordinator

Interview with Meneca de Mencía, President HRCD

Interview with María Elisa Alvarado, General Director HRCD

Interview with Nelson Aly, Federation delegate

Travel Tegucigalpa - Miami

Peer reviewer Dr Salvador A. Molina:

Saturday 18.12.2004

Travel Miami - Frankfurt

Sunday 19.12.2004

Travel Miami - Frankfurt - Almaty

Monday 20.12.2004

Briefing by Drina Karahasanovic, Regional Federation Programme Coordinator 
Interview with Sholpan Ramazanova, Head of Department youth \& health programmes KRCS

Interview with Dr. Vadim Kadyrbaev, Vice-President KRCS

Interview with Dr. Ophelia Kachatryan, peer reviewer, Head of Health Department Armenian Red Cross

Tuesday 21.12.2004

Interview with Zamira Shumagulova, Harm reduction project manager and Shasha, volunteer Interview with Dr. Lebedev Yevgeni, director AIDS Centre Almaty

Interview with Kulyan Ichshanova, Head of co-ordination for branch activities, KRCS

Wednesday 22.12.2004

Interview with Dr Mukushev Nurlan, Chief doctor of antituberculosis municipal dispensary Almaty

Group interview with inpatients of antituberculosis municipal dispensary

Interview with Timothy Cummings, Head of project delegation American Red Cross

Interview with Sholpan Ramazanova, Head of Department youth \& health programmes

KRCS

Interview with Shnar Baitassava, Youth co-ordinator KRCS

Interview with Dr. Ophelia Kachatryan

Between Tuesday 21.12.2004 and Wednesday 22.12.2004, Dr. Ophelia Kachatryan conducted two personal and eight telephone interviews with:

I. Galina Belova, head of a regional (oblast') branch of the Kazakhstan Red Crescent, Ust'- Kamenogorsk.

II. Serik Kojabekov, coordinator of TB project (6 programs), HQ, Almaty (personal interview).

III. Elena Kim, psychologist, training specialist of health programs of the Kazakhstan Red Crescent, HQ, Almaty (personal interview).

IV. Gyulnara Kamidenova, coordinator of AIDS prevention program, Karaganda.

V. Aygul' Kumasheva, AIDS prevention program coordinator, Astana.

VI. Lyaylya Amrenova, AIDS prevention program coordinator, Ust'-Kamenogorsk

VII. Elena Krokus, TB program coordinator, Semipalatinsk

VIII. Elena Vorotinceva, TB program coordinator, Kokshetau.

IX. Natalya Snejina, volunteer of AIDS prevention program, Astana.

X. Daniyar Batirbaev, volunteer of AIDS prevention program, Semipalatinsk.

Thursday 23.12.2004

Travel Almaty - Zürich

Friday 24.12.- Friday 31.12.2004: off

Saturday 1.1.- Sunday 2.1.2005

Travel

Zürich-

Windhoek

Monday 3.1.2005

Interview with Razia Essack - Kauaria, Secretary General Namibian Red Cross Society (NRCS)

Interview with Shannon Schroeder, financial manager NRCS

Interview with Dr Helena Ndume, Chairperson NRCS 
Interview with Naemi Heita, project manager NRCS (Recruiting of patients for anti-retroviral therapy)

Interview with Christiaan Wimmert, project manager NRCS (HIV/AIDS, TB and malaria prevention)

Tuesday 4.1.2005

Interview with Abel Augustinio, Programme manager NRCS

Interview with Dr Pia Appelgren, Federation HIV/AIDS delegate

Interview with Pierre van Niekerk, Managing Director Diamond Health Services

Interview with Emma Emma Tuahepa, chairwoman of an NGO of PLWHA

Interview with Dr Desta and Dr Eyob, WHO Namibia

Interview with Khin-Sandi Lwin, representative UNICEF, Namibia

Wednesday 5.1.2005

Daytrip to Caprivi with Namibia Airlines

Interview with Wilhelmina Khafitha, MoH RN working with HIV/AIDS

Interview with Dr Samasika Kabanje, Principle Medical Officer MoHSS, Caprivi

Group interview with three RC volunteer women (one care giver and two facilitators)

Interview with Polly Helmut, Regional Manager NRCS Caprivi

Short visit to NRCS VCT centre New Start Caprivi

Thursday 6.1.2005

Interview with

Group interview with nine volunteers (eight female, one male) from Komastal and Kilimanjaro neighbourhood.

Three home visits each to clients in Khomastal and Kilimanjaro neighbourhood.

Interview with Sister Alleta, Registered Nurse in MoH clinic Khomastal

Interview with Ferdrika Herero, Regional Manager NRCS Komas and project manager homebased care

Friday 7.1.2005

Interview with Abel Augustinio, Programme manager NRCS

Travel Windhoek-Frankfurt

Saturday 8.1.2005

Travel Frankfurt- Zurich

Sunday 9.1.2005

Travel Zurich - Oslo

Monday 10.1.2005

Interview with Bente MacBeath, head of preparedness and health department, Norwegian Red Cross Society

Interview with Tor Ole Bergan, programme manager blood donation, NorCross

Interview with Morten Lysebo, ambulance service manager NorCross

Interview with Anne Merete Bull, health adviser NorCross, and Bente MacBeath

Interview with Helene Vikan, relief co-ordinator NorCross

Travel to Sarpsborg 
Tuesday 11.1.2005

Interview with Øyvind Bruflat, district district secretary NorCross

Interview with Øyvind Gandrud, public ambulance service, and Karin Nordby, deputy district secretary NorCross

Travel to Mysen

Interview with Arild Bodal and Tore Aames, NorCross branch Mysen

Travel to Oslo

Interview with Olav Aasland, First-Aid co-ordinator NorCross

Wednesday 12.1.2005

Interview with Turid Dankertsen, head of Knowledge-sharing and Volunteer Development, and Elin Bjor, head of unit, NorCross

Interview with Eva Erikson, head of Children's Relief NorCross

Interview with Katinka Steenstrup, head of Visitors' Service in Prisons, NorCross

Interview with Laila Thiis Stang, Secretary-General of 'Pluss' - Association against AIDS

Interview with Kjell Arne Langseth, head of Stop Violence, NorCross

Interview with Hilde Bryna, development consultant for Youth, NorCross

Travel Oslo - Zurich

Thursday 13.1. - Friday 14.1.2005

Zurich - São Paulo

Between Wednesday 19 and Monday 31 January, telephone interviews were held with the following respondents: Dr Massimo Barra (Health Advisor Italian RC, Vice-president of Federation), Evelin Lacsina (Manager of community health and nursing services Philippine RC), Dr Ariel Kerstens (Cruz Roja Argentina), Dr Francisco Moreno (Director General de Salud Cruz Roja Colombiana), Kristiina Kumpula (Secretary General Finnish RC), Dr Bildad Boguma (H\&C Ugandan RC), Amelia Gabba (health co-ordinator Sierra Leone RC), Dr Freddy Karup Pedersen (President, Danish RC) Fernanda Teixeira (Secretary General CV do Moçambique), Dr Leong Seong Kwok (Manager, Services Singapore Red Cross) and Martin Fuhrer (International Co-operation, Swiss RC)

\section{Mission to Lagos, Nigeria, $21^{\text {st }}-24^{\text {th }}$ November 2004}

Team members: Dr Inon Schenker, consultant and Dr Asha Mohammed, peer reviewer Kenyan Red Cross

Site visit were made to the Lagos state branch offices, clinic and home for abandoned babies

\section{Persons interviewed:}

1. Mr Emmanuel I. Ijewere

2. Dr.(Mrs) O.A.Odiakosa

3. Mr. Abiodun Orebiyi

4. Mr. Abubakar Kende

5. Dr. Aderanti Adekunle

6. Mr. Dan A. Usman

7. Dr. Olubunmi Adebiyi

8. Mr. Timothy Oladele
National President

National Health Advisor

Secretary General

Asst. SG Programmes

Principal Health Officer

Zonal Health Officer(N.W)

Zonal Health Officer (S.W)

Branch Chairman (Lagos State) 
Strategy 2010 - Health \& Care Review

9. Lynn-Lila Mawusi-Halm

10. Alyson Lewis

11. Mr. Kabir Ahmed

12. Mr. Mesfin Halefom

13. Mr. Emmanuel Campbell

14. Mothers' Club members
Branch Secretary (Lagos State)

IFRC Health Delegate

IFRC Finance Devt. Delegate

IFRC OD Delegate

ICRC Cooperation Delegate

Lagos State branch 